(C) Dereito Vol.28, n01:109-145 (Xaneiro-Xuño, 2019) • ISSN 1132-9947

\title{
LA DIMENSIÓN PROCESAL DE LA CALIFICACIÓN CONCURSAL
}

The procedural dimension in insolvency proceedings

DOI: http://dx.doi.org/10.15304/dereito.28.1.4615

PABLo DoAllo RodRíguez ${ }^{1}$

Doctorando en Organización Jurídica del Mercado

Universidade de Vigo

pablo.doallo@gmail.com

\section{Resumen}

Las sucesivas modificaciones de la Ley 22/2003, Concursal, han ido actualizando los cauces procesales del concurso para modernizarlos y adaptarlos a un contexto de grave crisis económica. Una de las materias que ha recibido una atención especial por parte del legislador es la calificación del concurso, cuyo objeto es depurar las posibles responsabilidades de quienes estaban a cargo de la gestión del negocio, y que condujeron a la situación de insolvencia. La sección sexta es el iter procesal destinado a originar un pronunciamiento judicial sobre la calificación, y se forma como pieza separada dentro del proceso concursal. En este estudio intentaremos exponer detalladamente los diferentes hitos procesales de la sección sexta, lanzando una mirada interpretativa pero también crítica de los preceptos que regulan el desarrollo de la sección y que están contenidos en el Capítulo II del Título VI de la Ley Concursal.

Palabras clave: Concurso de acreedores; calificación del concurso; sección sexta.

\section{Abstract}

The legislative reforms following the passing of Spanish Insolvency Act in 2003 have contributed to actualize the procedural rules in order to make them more up-to-date and adjusted to a scenario of profound economic crisis. One of the subjects that has received a special regard by the legislator is the "rating" of the bankruptcy, which is aimed at determining liabilities of those who were in charge of the business, and led it to insolvency (the rating will decide the bankruptcy as being caused by misfortune or guilt). The sixth section is the procedural road that leads to the judicial decision on the rating, and it is formed as a separate nub inside the bankruptcy procedure. In this paper we will strive to show in detail all different stages of the sixth section, with an interpretative but also critical glance at the articles that define the development of the section, contained in Chapter II of Title VI of the Act.

Keywords: Insolvency proceedings; Rating of bankruptcy; Sixth section.

${ }^{1}$ https://orcid.org/0000-0003-0580-8044

Recibido: 28/09/2018. Aceptado: 15/11/2018. 


\section{SUMARIO}

1.- INTRODUCCIÓN. 2.- PRESUPUESTOS PROCESALES DE LA CALIFICACIÓN. 2.1.- La formación de la sección sexta: momento, supuestos y límites. 2.1.1.- Momento procesal de apertura de la sección. 2.1.2.- El convenio gravoso como exigencia para la formación de la sección. 2.2.- Los participantes en la sección sexta y las alegaciones iniciales. 2.2.1.- La personación inicial en la sección sexta. 2.2.2.- La figura del interesado en la sección sexta. 2.2.3.- El atípico status procesal de acreedores e interesados. 2.2.4.- Naturaleza y contenido del escrito de alegaciones del 168 LC. 2.3.- Tramitación de la sección sexta. 2.3.1.Informe de la administración concursal: plazo. 2.3.2.- Informe de la administración concursal: contenido. 2.3.3.- Dictamen del Ministerio Fiscal. 2.3.4.- Vinculación del juez a la calificación conjunta de concurso fortuito. 2.3.5.- Calificación provisional de culpabilidad. 2.3.6.- Oposición a la calificación. 3.- SENTENCIA DE CALIFICACIÓN, RECURSOS Y EJECUCIÓN. 4.- INCUMPLIMIENTO DEL CONVENIO, REAPERTURA DE LA SECCIÓN SEXTA. 5.- CONCLUSIONES. 6.- BIBLIOGRAFÍA.

\section{SUMMARY}

1.- INTRODUCTION. 2.- PROCEDURAL REQUISITES FOR BANKRUPTCY RATING. 2.1 Birth of the sixth section: timing, scenarios and limits. 2.1.1.- Procedural instant for the opening. 2.1.2.- Burdensome covenant as a requisite for the sixth section's opening. 2.2.- Participants in the sixth section and their initial allegations. 2.2.1.- Initial attendance in the sixth section. 2.2.2.- The stakeholder's figure. 2.2.3.- Untypical status of creditors and stakeholders. 2.2.4.- Nature and content of Article 168's statement of allegations. 2.3.- Processing of the sixth section. 2.3.1.Memorandum of bankruptcy administrators: deadline. 2.3.2.Memorandum of bankruptcy administrators: content. 2.3.4.- Judge's binding to the joint misfortunate rating. 2.3.5.- Provisional guilty rating. 2.3.6.- Opposition to the rating. 3.- JUDICIAL DECISION OF RATING, APPEAL AND EXECUTION. 4.- FAILURE TO COMPLY WITH THE COVENANT, REOPENING OF THE SIXTH SECTION. 5.- CONCLUSIONS. 6.BIBLIOGRAPHY.

\section{INTRODUCCIÓN}

La calificación del concurso implica la formulación judicial de una determinada apreciación sobre su causa. Así, la Ley Concursal en su artículo 163, distingue entre concursos de carácter fortuito y aquellos que han sido causados por un comportamiento doloso o culposo del deudor, y denomina a estos últimos "concursos culpables".

Esta ley, la 22/2003, de 9 de julio, Concursal (en adelante "LC"), no contiene una definición legal de la calificación concursal. La Exposición de Motivos comienza por expresar directamente los supuestos en los que queda excluida la calificación, expresando que no tendrá lugar más que cuando ocurra: <<la aprobación de un convenio que, por la cuantía de la 
quita o la duración de la espera, resulte especialmente gravoso para los acreedores, y la apertura de la liquidación $>>^{2}$.

Esta atribución de responsabilidad sobre el concurso se estructura de acuerdo con presupuestos materiales y procesales, regulados conjuntamente en el Título VI de la Ley Concursal. A estos últimos dedicamos fundamentalmente el presente estudio. Los preceptos procesales que se refieren a la sección sexta, aunque han sido abundantemente comentados, han despertado quizás menos atención.

Esta LC tiene, según su exposición de motivos, una vocación puramente reformadora de la legislación concursal, que se encontraba entonces aquejada de arcaísmo y dispersión de las normas vigentes. Éstos son defectos que derivan de la codificación española del siglo XIX, estructurada sobre la base de la dualidad de códigos de derecho privado, civil y de comercio, y de la regulación separada de la materia procesal respecto de la sustantiva, en una Ley de Enjuiciamiento Civil.

Así, encontraremos en esta Ley disposiciones de carácter tanto sustantivo como adjetivo, lo que, según veremos puede dar lugar a ciertos problemas interpretativos. Según expone la LC:

2 Esta consideración general de la Exposición de Motivos representa un límite de mínimos, por debajo del cual no se materializará la pieza sexta del concurso, y que se encuentra recogido en el artículo 167.1 de la LC, que dispone: <<no procederá la formación de la sección de calificación del concurso cuando tenga lugar la aprobación judicial de un convenio en el que se establezca, para todos los acreedores o para los de una o varias clases, entendiendo igualmente por tales las establecidas en el artículo 94.2, una quita inferior a un tercio del importe de sus créditos o una espera inferior a tres años, salvo que resulte incumplido $>>$.

La ratio legis que llevó al legislador a establecer este mínimo no podemos encontrarla en la defensa del interés del acreedor, puesto que al acreedor, en muchos casos, le interesará acceder directamente al patrimonio del deudor o administrador culpable del concurso antes que aceptar las quitas y esperas del convenio, y, en todo caso, antes que esperar a un incumplimiento del convenio para que sea posible tramitar la pieza sexta, ex artículo 167.2 de la LC, para exigir la totalidad de su derecho de crédito (sin los beneficios del convenio). Por otro lado, la valoración de la quita o la espera como "especialmente gravosas" para el acreedor, lo que dependerá de cada acreedor, es juicio cuyo contenido viene por fortuna delimitado por el legislador, que ha realizado una interpretación auténtica de lo que debemos considerar como especialmente gravoso.

Creemos, contrariamente, que esta disposición pone en relación la entidad de la conducta dolosa o culposa con el perjuicio causado al acreedor, lo que conlleva, quizás, una especie introducción del principio de intervención mínima, en lo que serían términos del derecho penal.

Debemos recordar asimismo que, en este sentido, el TRLSC se refiere en su artículo 226 a la protección de la discrecionalidad empresarial de los administradores en el ámbito de las decisiones estratégicas y de negocio, ello desde la modificación operada en 2014, que supuso la elevación a disposición legal de la doctrina conocida como la business judgement rule. Esto es también un límite al control jurisdiccional de las decisiones de administración. Por lo tanto, el foco del análisis judicial no está directamente encaminado, ni en el ámbito del TRLSC ni en el de la LC, a sustituir el criterio del administrador, sino más bien a constatar que las decisiones, acertadas o erróneas se tomaran de acuerdo a un estándares mínimos de diligencia. Basta una rápida lectura de los artículos 164 y 165 LC para comprobar que esto es así, quizás con la excepción de los socios que se niegan sin causa razonable a la capitalización de créditos. 
$<<$ La superación de la diversidad de instituciones concursales para comerciantes y no comerciantes es una fórmula que, además de estar justificada por la desaparición del carácter represivo de la insolvencia mercantil, viene determinada por la tendencia a simplificar el procedimiento, sin que ello suponga ignorar determinadas especialidades del concurso de los empresarios sometidos a un estatuto propio (llevanza obligatoria de contabilidad, inscripción en el Registro Mercantil) y de la existencia en la masa activa de unidades productivas de bienes o de servicios, especialidades que son tenidas en cuenta a lo largo de la regulación del concurso, desde su solicitud hasta su solución mediante convenio o liquidación >>.

También simplifica la LC la estructura orgánica del concurso. Sólo el juez y la administración concursal constituyen órganos necesarios en el procedimiento. La junta de acreedores únicamente habrá de constituirse en la fase de convenio cuando no se haya aprobado por el sistema de adhesiones escritas una propuesta anticipada. La intervención como parte del Ministerio Fiscal se limita a la sección sexta, de calificación del concurso, cuando proceda su apertura, sin perjuicio de la actuación que se establece la propia LC cuando intervenga en delitos contra el patrimonio o el orden socioeconómico.

En este estudio examinaremos a fondo la tramitación de la sección sexta, dedicando el capítulo más extenso a esta tarea. A la sentencia de calificación dedicaremos unos pocos párrafos, puesto que su regulación desborda ampliamente el campo procesal, aunque sí expondremos los posibles recursos que caben contra ella, así como el modo de alcanzar su ejecución. Cerraremos el trabajo con el estudio de la reapertura del concurso, de enorme trascendencia práctica.

\section{PRESUPUESTOS PROCESALES DE LA CALIFICACIÓN 2.1. La formación de la sección sexta: momento, supuestos y límites}

El procedimiento concursal está dividido en varias secciones dedicadas a cuestiones específicas. La sección sexta, relativa a la calificación concursal, deberá ser conformada por el juez en función de determinadas premisas, contempladas en el artículo 167 LC.

\subsubsection{Momento procesal de apertura de la sección}

Comienza este artículo por establecer en qué punto del proceso concursal debe ser ordenada la formación de esta sección, y establece tres eventos que marcan su apertura: (i) la aprobación del convenio de acreedores ${ }^{3}$, (ii) la aprobación del plan de liquidación y (iii) la orden de liquidación de acuerdo con las normas supletorias ${ }^{4}$.

\footnotetext{
3 La aprobación del convenio, en base al artículo 129 LC, deberá adoptar la forma de sentencia, que además debe ser publicada en los términos de los artículos 23 y 24.

${ }^{4}$ Dos son las posibilidades previstas respecto de la resolución que acuerda la liquidación:

a) Que se acuerde la apertura junto con la resolución que apruebe el plan de liquidación. Esto implica que, con anterioridad, deberá haber sido dictado el auto de apertura de la liquidación, regulado en el artículo 140 LC. Este auto abre el procedimiento de liquidación, tras lo cual deberá ser presentado un informe por la
} 
Cabe preguntarse en primer lugar si, teniendo en cuenta la dicción del artículo 167, es necesario que con carácter previo a las resoluciones judiciales descritas haya sido declarado judicialmente el concurso o si se requiere al menos que haya sido admitida a trámite la solicitud del concurso.

Esta cuestión adquiere una gran relevancia en aquellos casos en los cuales existe una propuesta anticipada de convenio que se presenta junto con la solicitud de concurso voluntario, ex artículo 104 LC. ¿Cabe la apertura de la sección de calificación en ese momento (con la resolución judicial que apruebe la propuesta anticipada) o deberá conformarse la sección tan sólo si dicho convenio resulta incumplido?

Hay que considerar en primer lugar que el artículo 106.2 LC dispone que: $<<$ Cuando la propuesta anticipada de convenio se presentara con la solicitud de concurso voluntario o antes de la declaración judicial de éste, el juez resolverá sobre su admisión en el mismo auto de declaración de concurso [...] >>. Por lo tanto, la "resolución judicial" que apruebe la propuesta anticipada será la misma que declare por imperio del artículo 167 la formación de la sección sexta: el auto de declaración de concurso. Así lo interpreta también el profesor DE MIQUEL, que entiende que la ley no distingue entre convenios ordinarios y anticipados, y que cumpliéndose los requisitos, procede en ambos casos la apertura de la pieza de calificación ${ }^{5}$.

Por tanto, no cabe formar la sección sexta sin previa o simultánea declaración de concurso. La única excepción que podemos encontrar se refiere a la calificación en caso de intervención administrativa, siempre que las medidas adoptadas excluyan la posibilidad de declarar el concurso ${ }^{6}$.

administración concursal para la realización de los bienes y derechos de la masa activa. De acuerdo con el artículo 148 LC, el deudor y los acreedores tienen un plazo de 15 días para formular observaciones o propuestas de modificación. Seguidamente, el juez resolverá mediante auto la aprobación del plan de liquidación incluyendo o no las modificaciones propuestas. Será esta última resolución la que ordene la apertura de la sección sexta.

El ínterin entre el primer auto y el segundo es también un buen momento para que los administradores concursales o los acreedores reúnan información que luego podrán aportar en la sección sexta. J. DE MIQUEL BERENGUER: La Pieza de Calificación en el Concurso de Acreedores, Bosch, Barcelona, 2012.

b) Que se acuerde la apertura en la resolución que ordena la liquidación según las normas subsidiarias. Dicha modalidad, prevista en artículo 149 LC, consiste en una serie de disposiciones que bien regulan la liquidación con carácter subsidiario al plan o bien actúan en defecto de plan, cuando éste no es aprobado por el juez. La decisión que dará lugar en este caso a la apertura de la sección sexta es el mismo auto regulado en el artículo 148.2 LC, y cuyos trámites previos acabamos de describir.

5 J. DE MIQUEL BERENGUER: La Pieza de Calificación en el Concurso de Acreedores, Bosch, Barcelona, 2012, p. 25.

${ }^{6}$ Vid. artículo 174 de la Ley Concursal. 


\subsubsection{El convenio gravoso como exigencia para la formación de la sección}

Además de establecer el momento procesal de la apertura de la sección de calificación, es importante destacar que el artículo 167 configura este trámite como un deber inexcusable del juez mercantil, sin que quede condicionada de este modo a la voluntad de las partes personadas (deudor, administradores concursales, acreedores, etc.), y siempre que se cumplan los requisitos.

Ya nos referimos someramente en la introducción del presente trabajo al requisito primordial exigido por el artículo 167.1 LC, que reza en su párrafo segundo: <<Por excepción a lo establecido en el apartado anterior, no procederá la formación de la sección de calificación del concurso cuando tenga lugar la aprobación judicial de un convenio en el que se establezca, para todos los acreedores o para los de una o varias clases, entendiendo igualmente por tales las establecidas en el artículo 94.2, una quita inferior a un tercio del importe de sus créditos o una espera inferior a tres años, salvo que resulte incumplido >>.

Ahora bien, ¿a qué clases de acreedores se refiere el artículo? La remisión al artículo 94.2 LC no es limitativa, puesto que dice en su forma literal "entendiendo igualmente".

Este límite a la valoración judicial de las causas del concurso, que no estaba contenido en la versión original de la Ley Concursal, fue introducido por la Ley 38/2011, de 10 de octubre. En la redacción dada por esta ley, la quita o espera reducida debía predicarse de "todos los acreedores o para los de una o varias clases". Esta mención genérica de las "clases" que serían computables a efectos de calificación llevó a la práctica judicial a incluir en una misma clase a un grupo de acreedores que reúnan características comunes, aunque tal grupo no comprenda a todos los de la misma clasificación concursal.

No obstante, el legislador expresa en las sucesivas reformas de la Ley Concursal, llevadas a cabo por el Real Decreto-ley 11/2014, de 5 de septiembre y la Ley $9 / 2015$, de 25 de mayo, su voluntad de combinar las clases a efectos del convenio gravoso con la definición general de las clases de acreedores ${ }^{7}$.

Para ello introduce la referencia al artículo 94.2 LC, que a su vez establece su propia clasificación (laborales, públicos, financieros y otros).

El artículo 167 se refiere expresamente a la aprobación de un convenio "para todos los acreedores o para los de una o varias clases". Se desprende de ello que, en principio, basta con que el convenio resulte no gravoso para una sola de las clases referidas, incluyendo asimismo las

\footnotetext{
7 Es verdaderamente dudosa la técnica legislativa desplegada en la actualización del artículo 167 LC, la Ley 9/ 2015 es redundante con respecto a la modificación del RDL de 2014. Si se revisan las redacciones dadas al artículo 167 por ambos textos legales, resulta que sólo se diferencian en una letra mayúscula de la palabra "Capítulo". Como se irá describiendo a lo largo de esta obra, no será ésta ni la única ni la peor de las tachas, omisiones e incongruencias a las que ha dado lugar la deficiente redacción de las normas procesales referidas a la sección sexta.
} 
clases de acreedores según su crédito (artículo 134 LC), para impedir la formación de la sección sexta.

La propia Exposición de Motivos del Real Decreto-ley 11/2014, de medidas urgentes en materia concursal, para el caso de que el convenio afecta tanto a acreedores ordinarios como privilegiados dice: <<Habida cuenta que el artículo 94.2, en la redacción dada por esta Ley, incorpora una nueva definición del término «clase» aplicable, conforme al artículo 134, a los supuestos en que el convenio llegara a arrastrar a acreedores privilegiados y no exclusivamente a los ordinarios, es imprescindible aclarar, para evitar mayores dudas, que la mención que se efectúa en el artículo 167 debe entenderse también referida a esta definición, que afecta a una pluralidad de acreedores beneficiados por la solución concursal lo suficientemente amplia como para hacer equivalente el tratamiento a efectos de la sección de calificación $>>$.

Cabe preguntarse asimismo qué ocurre cuando no se cumple el requisito del carácter gravoso del convenio. Está claro que la norma no mantiene ya el carácter imperativo que ordena la apertura de la sección, pero ¿puede aun así el juez, no por obligación legal, sino motu proprio, dar inicio aun así a la sección?

Pues bien, en caso de que no se cumpla el requisito, hay que concluir que queda fuera de las facultades del juez declarar la formación de la calificación, y ello por aplicación estricta del principio de legalidad procesal, consagrado en el artículo 1 de la Ley de Enjuiciamiento Civil como una de las garantías fundamentales en las actuaciones judiciales ${ }^{8}$.

\subsection{Los participantes en la sección sexta y las alegaciones iniciales}

2.2.1. La personación inicial en la sección sexta

El juez y la administración concursal son órganos esenciales del procedimiento, según enuncia la Exposición de Motivos de la LC, y, concretamente, la administración concursal, tanto si actúa en el concurso como interventora o propiamente como administradora, tiene aquí un papel muy señalado.

No puede faltar asimismo el propio deudor, personificado en los miembros de los órganos de administración en caso de que sea una persona jurídica, así como los liquidadores, si los hay. Especialmente relevante es la participación que la ley confiere al Ministerio Fiscal, quien, como veremos, debe emitir dictamen a la vista de los autos de la sección y del informe de la administración concursal.

\footnotetext{
8 No podemos negar que el Juez de lo Mercantil goza de una especial esfera de facultades, como se extrae de una pausada lectura de la LC (por ejemplo artículo 48.4 LC), y además rige hasta cierto punto el principio inquisitivo, puesto que los intereses tutelados por el órgano judicial superan a los meramente privados, y se pueden encontrar también en la defensa de intereses públicos y del orden socioeconómico, y ahí encuentra justificación también la intervención como parte del Ministerio Fiscal. No obstante, es clarísima la voluntad del legislador de establecer un límite de mínimos con la reforma del artículo 167 por la Ley 38/2011, que así lo expresa en su Exposición de Motivos.
} 
Sin embargo, quien primero puede intervenir en la sección sexta una vez declarada su apertura no es ninguno de ellos. El turno corresponde a los acreedores y demás sujetos que, sin ser acreedores, ostentan algún interés. Éstos no son parte imprescindible de la sección de calificación y, consecuentemente, deberán formalizar el trámite de personación, al cual unirán sus alegaciones.

El artículo 168.1 LC dispone que: <<Dentro de los diez días siguientes a la última publicación que se hubiera dado a la resolución que acuerde la formación de la sección sexta, cualquier acreedor o persona que acredite interés legítimo podrá personarse y ser parte en la sección, alegando por escrito cuanto considere relevante para la calificación del concurso como culpable $>>^{9}$.

Cualquier acreedor ostenta legitimación para comparecer en la sección sexta. Deben entenderse incluidos, por supuesto, los comprendidos en la lista de acreedores del concurso cuya conformación corresponde a la administración concursal, merced al artículo 86 LC: <<Corresponderá a la administración concursal determinar la inclusión o exclusión en la lista de acreedores de los créditos puestos de manifiesto en el procedimiento. Esta decisión se adoptará respecto de cada uno de los créditos, tanto de los que se hayan comunicado expresamente como de los que resultaren de los libros y documentos del deudor o por cualquier otra razón constaren en el concurso $>$.

No obstante, si la administración concursal no ha presentado el informe del artículo 86 LC, entendemos que nada obsta a la personación de acreedores en la sección sexta, pero tendrán que justificar tal condición, del mismo modo que los interesados deben acreditar la suya.

2.2.2. La figura del interesado en la sección sexta

Al margen de la referencia al acreedor, es de enorme importancia que esté prevista la formulación de alegaciones al inicio de la sección sexta por parte de "cualquier persona que acredite un interés legítimo". La falta de delineación de la figura del interesado a efectos del artículo 168 ha motivado un amplio desarrollo del concepto tanto desde los tribunales como desde la doctrina.

En primer lugar, con carácter general existen una serie de personas tanto físicas como jurídicas que ostentas per se la condición de interesados en el procedimiento concursal ${ }^{10}$ : el cónyuge de la persona concursada, terceros adquirentes de bienes o derechos susceptibles de ser objeto de rescisorias concursales, sociedades integrantes del mismo grupo que la persona concursada, etc.

No obstante, el interesado de la sección sexta lo es sólo en aras a la calificación del concurso como culpable. Esto descarta la concurrencia en

\footnotetext{
${ }^{9}$ En lo que falte por decir sobre del dies a quo, que es día de la última publicación de la resolución que acuerda la apertura, nos remitimos a la nota al pie no 6 .

$10 \mathrm{~J}$. AZAGRA, R. TAGLIAVINI, La posición procesal del adquirente de unidades productivas en concurso de acreedores, Uría Menéndez, p. 15, disponible en: http://www.uria.com/documentos/publicaciones/4290/documento/tavUM.pdf?id=5502 (Consultado 19.02.2018).
} 
la posición de interesado del deudor, de los sujetos anteriormente descritos, y en general de todos aquellos que procuren la calificación del concurso como fortuito.

En segundo lugar, y refiriéndose específicamente a la sección sexta, se intentado definir el presupuesto que determina la existencia el interés legítimo, y los tribunales han considerado que se identifican exclusivamente con la existencia de un perjuicio o gravamen para el propio interesado ${ }^{11}$. No obstante, según un auto de la Audiencia Provincial de Madrid, aunque dichos intereses pueden englobar intereses "indirectos, potenciales o futuros", no se considera presupuesto suficiente para considerarse interesado la defensa de intereses ajenos o la mera corrección del informe.

Al juez del concurso le corresponde la valoración en cada caso, y sin pauta legal alguna, de la concurrencia de interés legítimo en el tercero que solicita que se le tenga por personado y parte en la sección de calificación ${ }^{12}$. Ello implica, además, que el escrito de personación y alegaciones debe contener los hechos o valoraciones que puedan confirmar al juez el efectivo interés, y que éste lo sea en una potencial calificación de culpabilidad.

Conviene plantear si la noción de interesados podría incluir a los administradores de hecho, quienes en muchos casos poseen información relevante a efectos de calificación desconocida por la administración concursal, o por el órgano formal de administración (o el empresario persona física). El interés legítimo del administrador de hecho es patente, toda vez que, de ser calificado el concurso como culpable, podría resultar sancionado con inhabilitación o incluso con responsabilidad patrimonial por los daños y perjuicios causados a la masa activa del concurso. Lo mismo habría de predicarse respecto de los apoderados generales y de aquellos que puedan ser considerados cómplices.

Estos sujetos que pueden resultar afectados por la calificación serán llamados a intervenir en el procedimiento por imperio del artículo 170.2 LC, que analizaremos en apartado siguiente, pero nada obsta a que se personen con anterioridad, puesto que dice en sus propios términos que

\footnotetext{
${ }^{11}$ Es el Auto de la Audiencia Provincial de Madrid, Sec. 28a, de 4 de diciembre de 2008 (Ponente: Rafael Sarazá Jimena). Éste analiza el concepto de interesado poniéndolo en relación con el artículo 96 LC y (i) confirma la amplitud de la noción de interesado, (ii) identifica la necesaria existencia de un perjuicio o gravamen para el propio interesado como presupuesto esencial para justificar la existencia de interés legítimo. Dice el Auto: $<<$ En opinión de la Sala, la expresión "cualquier interesado" ha de considerarse una expresión más amplia que la de "titular de un derecho subjetivo" y que la de "titular de un interés directo". Pero ha de tratarse de un sujeto de derecho con un interés propio, que no puede identificarse con un interés en la defensa abstracta de la corrección del informe ni con la defensa de intereses ajenos>>. Añadiendo que: <<para convertirse en una aptitud real y efectiva que le dote de la oportuna legitimación, un añadido: que los extremos objeto de impugnación supongan, para el impugnante, algún tipo de perjuicio o gravamen, aunque no sea necesariamente directo, real y actual, sino también, como consecuencia de la amplitud de la expresión utilizada, indirecto, potencial o futuro >>.

$12 \mathrm{~J}$. AZAGRA, R. TAGLIAVINI, La posición procesal del adquirente de unidades productivas en concurso de acreedores, Uría Menéndez, pp. 13-14.
} 
deberán ser emplazados para que comparezcan en la sección "si no lo han sido con anterioridad".

Ahora bien, el artículo 168 se refiere a aquellos que aleguen "cuanto consideren relevante para la calificación del concurso como culpable". Esto elimina la posibilidad de ofrecer una cierta ayuda al deudor (o a sí mismos, en caso de administradores de hecho, cómplices o apoderados ${ }^{13}$ ). A su vez, ese inciso del artículo 168, como hemos visto, nos conduce a interpretar que el trámite inicial de alegaciones queda reservado para aquellos cuyo interés legítimo no está en su propia defensa, sino en sus potenciales derechos frente al concursado y quienes resulten responsables del concurso culpable.

Pese a ello, estimamos que no se puede descartar la personación de aquellos que pueden resultar afectados por la calificación culpable. En otro supuesto, podría ocurrir que, por ejemplo, un miembro del consejo de administración de la concursada -que podría resultar a priori responsable concursal- decida poner de manifiesto ciertas irregularidades llevadas a cabo por el director financiero y el consejero delegado, creyendo que la restitución a la masa activa podrá salvar a la compañía de la liquidación.

En este sentido, no encontramos obstáculo legal que lo impida. Por un lado, lo dispuesto por el artículo 170 abre la vía para la comparecencia de estos sujetos en la sección con anterioridad al trámite de oposición.

13 Estos sujetos, dado que tienen legitimación (pueden resultar afectados por una calificación culpable), podrían utilizar las alegaciones del 168 como estrategia procesal, para ayudarse efectivamente "a sí mismos" de una forma indirecta. Veamos cómo:

La dicción del artículo 168 LC impide que presenten alegaciones exculpatorias. A pesar de ello, como suele decirse: la mejor defensa es un buen ataque, y no debemos ignorar la posibilidad de que estos sujetos puedan inculparse unos a otros utilizando el mecanismo de las alegaciones iniciales, en un intento de influir en los informes posteriores de la administración concursal y Ministerio Fiscal, para centrar el foco de la responsabilidad en algún otro sujeto.

Queda la pregunta de si cabría que esta parte recurriera la sentencia de calificación que no lo considera culpable ni cómplice. Entiendo que no. Opino que la posición procesal del interesado se mantiene en la medida en que su propio interés pervive, que en este caso es la posibilidad de que se declare la propia responsabilidad. Una vez que la sentencia ya ha decidido que no se es responsable, la condición de parte se desvanece al tiempo que el interés (podría hablarse incluso de pérdida del objeto litigioso). Es más, si del informe de la administración concursal y del Ministerio Fiscal no se deduce que puede tener responsabilidad el sujeto en cuestión ¿̇le debe ser conferido a éste trámite para que se oponga? Dado que el juez se encuentra vinculado al contenido de los informes por el principio de congruencia, hay que entender que no, es decir, que estos sujetos perderán lógicamente la posibilidad de oponerse, y dejarán de ser interesados en la sección.

No podemos hablar sin embargo de una auténtica excepción al artículo 172.4 LC, que dispone: <<Quienes hubieran sido parte en la sección de calificación podrán interponer contra la sentencia recurso de apelación >>. En este caso, entendemos que simplemente se inaplica dicho artículo. No debe parecer esto extraño, si recordamos que un acreedor que enajenara su crédito se vería privado de su posición en el concurso, por efecto de la sucesión procesal por transmisión del objeto litigioso (artículo 15 LEC). Del mismo modo, un administrador de hecho cuyo presupuesto de acción se circunscriba a la potencial responsabilidad en el concurso, perderá la condición de interesado en cuanto quede fuera de las facultades del juez del concurso el declararlo culpable o cómplice. Ha perdido en ese momento vigencia la pretensión que amparaba su status, se ha perdido, en el fondo, el objeto litigioso en lo que a él atañe. 
Además, como hemos resaltado ya, los administradores de hecho, apoderados y posibles cómplices pueden estar en posesión de determinada información relevante (a estos efectos, tiene que ser información inculpatoria), y parece lo más conveniente permitir que tanto la administración concursal como el Ministerio Fiscal realicen el preceptivo informe a la vista de lo expuesto en el trámite inicial de alegaciones ${ }^{14}$.

Ya al margen de los administradores de hecho, cuando hablamos de interesados en la sección sexta a los efectos del artículo 168, que no ostentan un derecho de crédito contra el deudor, nos estaremos refiriendo mayoritariamente a los socios de la concursada. Éstos pueden haber visto traicionados en sus intereses de igual forma que los acreedores, habida cuenta de que el órgano de administración debe atender al interés de la sociedad cumpliendo los deberes fiduciarios que su cargo conlleva. Es innegable que la propia declaración del concurso, con lo que esto comporta, ya constituye en sí misma un perjuicio para su patrimonio, ello independientemente de que también la condición de socio otorga el derecho a participar del remanente de la masa activa, si es que no es adjudicada a los acreedores en su totalidad.

Por otro lado, como expone DE MIQUEL BERENGUER ${ }^{15}$, se deben aceptar como interesados a aquellos socios comerciales cuyas razonables expectativas se hubieran visto frustradas por el concurso. Sería el caso de una compañía distribuidora que proyecta junto con la concursada introducir sus productos en el país de ésta, abandonando la distribución en otros posibles territorios. Si por causa del concurso pierde sus expectativas, deberá asumir los costes de oportunidad sin contrapartida. Ello podría derivar en una acción de responsabilidad individual que, si prosperara, acabaría reconociendo la existencia de un crédito de la distribuidora frente a la masa.

No está de más poner de relieve qué puede ocurrir con aquellos sujetos cuyos propios intereses no se ventilan directamente en la pieza sexta, pero gozan de información relevante, y quieren utilizar el trámite de alegaciones para poner determinados hechos en conocimiento del juez, y (por qué no) para poder recurrir la sentencia de calificación en caso de que no sea de su agrado. Siempre será preciso demostrar el interés que se posea, particularmente cuando éste sea indirecto, potencial o futuro. Podría ser éste el caso de los empleados de la concursada, por ejemplo, no en cuanto a titulares de un derecho de crédito derivado de la relación laboral (entonces serían acreedores en pleno derecho), sino en cuanto a interesados generales en la restitución a la masa activa de los perjuicios causados.

\footnotetext{
${ }^{14}$ La preocupación porque la administración concursal disponga de toda la información relevante a efectos de calificación se expresa también en M. I. HUERTA VIESCA, D. RODRÍGUEZ RUIZ DE VILLA, "El plazo para la emisión del informe-demanda de calificación concursal del artículo 169.1 LC", Diario La Ley, No 8527, Sección Tribuna, 27 de Abril de 2015, Ref. D-159, LA LEY.

15 J. DE MIQUEL BeRENGUER: La Pieza de Calificación en el Concurso de Acreedores, Bosch, Barcelona, 2012, p. 39.
} 
Partimos de que la jurisprudencia no es afín a reconocer la posición de interesados en el proceso concursal a aquellos cuya ganancia o lesión sea completamente indeterminada o cuya actuación responda a algún deber moral o de custodia del interés ajeno ${ }^{16}$. Desde luego, entendemos que los empleados de la concursada defienden su propio interés (que se restituya el déficit a la masa activa del concurso, y salvar quizás a la entidad y con ello su puesto de trabajo), y en tal medida no debería ser óbice para considerarlos interesados que su potencial lucro o perjuicio sea de carácter indirecto.

No habría que descartar la presencia de los representantes de los trabajadores en la sección sexta. El Tribunal Constitucional ha tenido ocasión de pronunciarse a este respecto, en un caso en que se negó la intervención en la sección sexta tanto a varios trabajadores como a dos sindicatos, expresando que unos y otros albergan un interés legítimo ${ }^{17}$ : $<<$ La Ley concursal resulta diáfana al prever que se emplace a los terceros que puedan resultar afectados para que comparezcan en la sección a formular alegaciones. Por tanto, el Auto impugnado es claro que soslaya las previsiones establecidas por el ordenamiento que declaran que quien ha acreditado poseer un interés legítimo en el procedimiento pueda personarse en el mismo. La limitación de la actuación de los terceros con interés legítimo - en este caso, los aquí recurrentes- a la fase ulterior del contradictorio constituye una interpretación judicial que, apartándose de forma patente de las previsiones legales, restringe de manera constitucionalmente reprochable el derecho de acceso a la jurisdicción garantizado por el art. 24.1 CE>>.

A mi juicio, tales consideraciones no deben extenderse a las asociaciones, fundaciones, y demás entes con o sin personalidad jurídica que pretendan una defensa de intereses colectivos o difusos, 0 la de sus propios miembros ${ }^{18}$.

Este tipo de entidades responden a un fin propio no determinado legalmente $y$, aun si en ciertos casos este interés coincide con el interés público, entiendo que no es suficiente para legitimarlas, habida cuenta de que es el Ministerio Fiscal el verdadero defensor del interés público. A

\footnotetext{
16 J. AZAGRA, R. TAGLIAVINI, La posición procesal del adquirente de unidades productivas en concurso de acreedores, Uría Menéndez, p. 15.

17 Sentencia del Tribunal Constitucional 15/2012, de 13 de febrero de 2012 (Recurso de amparo 3313/2007).

${ }^{18}$ No hablamos en estos supuestos de legitimación basada en un interés indirecto, que bien podría tener encuadre en la figura de interesado, sino de un interés ajeno, que no lo tiene. Así, una asociación de consumidores, por ejemplo, o alguna asociación que pretenda ejercitar una suerte de acción popular en la sección se encontrarán con que el interés que persiguen, por elevado o encomiable que sea no les faculta para intervenir. Aunque es cierto que las asociaciones se constituyen con unas metas prestablecidas, y que tales fines son la base misma de su existencia, cuando batallan en el proceso buscan el cumplimiento de sus metas a través de la persecución de los intereses de sus asociados. Son éstos los verdaderos intereses que están en juego, pues son esos empleados, clientes, proveedores, socios y demás los que se verán beneficiados o perjudicados por la calificación. Son los intereses de éstos los que deben contar, y no los del ente que pretende englobarlos.
} 
diferencia de estas entidades, los representantes de los trabajadores y los sindicatos son, en el fondo, los destinatarios de una misión de orden constitucional: velar por los derechos de los trabajadores.

\subsubsection{El atípico status procesal de acreedores e interesados}

La Ley Concursal predica la condición de parte de los acreedores e interesados en el artículo 168, que se refiere a que ambos podrán "personarse y ser parte" en la sección. Sin embargo, de los artículos siguientes se deduce que la posición que ostentan en el proceso no es siquiera comparable a la de la administración concursal o el Ministerio Fiscal, quienes con su sola actuación pueden eliminar la competencia del juez del concurso para dictar una sentencia de calificación culpable.

Por otra parte, el artículo 168 se refiere de una manera especialmente vaga a la forma de intervención en la sección sexta de estos sujetos legitimados, expresando que participarán "alegando por escrito cuanto considere relevante para la calificación del concurso como culpable". Se plantean por tanto problemas en la interpretación del precepto en conexión con el verdadero alcance de esta posición procesal.

En primer lugar, la noción general de "partes" en el proceso, definida como tal en el artículo 10 de Ley de Enjuiciamiento Civil como quienes comparezcan y actúen en juicio como titulares de la relación jurídica u objeto litigioso, tiene un sentido absoluto. Resulta difícil entender que puedan existir grados con diferente intensidad dentro de la idea de parte procesal. Más correcto parece defender que la titularidad del objeto litigioso se tiene o no se tiene, sin que quepa término medio.

Ello, en consecuencia, coloca a los acreedores y sujetos interesados de la sección sexta en una posición procesal atípica. El examen de la auténtica naturaleza del status de los acreedores e interesados comporta ineludiblemente un juicio sobre la extensión de sus facultades procesales. Sobre esta cuestión ha habido cierto debate en la doctrina pero, sobre todo, en los tribunales, lo que ha llevado a pronunciamientos en diferentes direcciones.

Muchos autores comienzan analizando la problemática desde un punto de vista temporal, para dirimir si la reforma operada por el artículo 11.8 del Real Decreto-Ley 3/2009 supone una verdadera revisión de la posición del acreedor en la pieza sexta ${ }^{19}$. Con anterioridad a la citada reforma existían dos enfoques en relación con la cuestión. Bien se consideraba a los acreedores e interesados la condición de coadyuvantes o incluso la de parte (como una especie de intervención voluntaria de la LEC), siendo esta corriente la minoritaria, o bien unos y otros tenían como único papel dentro de la sección sexta el informar de determinados hechos o datos

\footnotetext{
${ }^{19}$ Real Decreto-Ley 3/2009, de 27 de marzo, de medidas urgentes en materia tributaria, financiera y concursal ante la evolución de la situación económica. Publicado en el BOE núm. 78, de 31/03/2009. Entró en vigor el 01/04/2009.
} 
que pudieran resultar de interés ${ }^{20}$. De acuerdo con esta segunda concepción, nunca podrían sus alegaciones conformar base jurídica que sirviera de fundamento a la sentencia de calificación.

La modificación operada en el año 2009 cambia la rúbrica del artículo 168, que pasa a estar encabezado por la expresión: "Personación y condición de parte". Algunos entienden que con eso basta para entender revisada la condición de los sujetos interesados en el procedimiento, y que éstos ahora llamados a participar en su plena condición de parte procesal. De este modo, concluye ROSENDE que: <<Así pues, los interesados serán, en todo caso, parte en el proceso de calificación a todos los efectos; pudiendo defender las pretensiones formuladas por su litisconsorte- la administración concursal y, en su caso, el Ministerio Fiscal- o las que él mismo formule e interponer los recursos que estime convenientes, con independencia de aquél $>>{ }^{21}$.

No obstante, si éste es el espíritu de la reforma, otros se plantean porqué se mantiene el trámite de alegaciones como actuación inicial. Sostiene, por ejemplo, FRAU I GAIÀ que como anteriormente la única misión de los acreedores e interesados era informar, resultaba acertado que sus escritos precedieran al informe de las partes. Ahora sin embargo, una vez conferido a los sujetos interesados el carácter de parte, sin embargo, entiende que: <<cuando esa inicial intención se desvirtúa y a los eventuales informantes se les otorgan - con más de un circunloquio que a la postre no ha evitado las consecuencias que se pretendía evitar - todos los derechos que se derivan procesalmente de su reconocida condición de parte, el sistema se resquebraja $>>^{22}$.

Por su parte, la reforma operada por la Ley 38/2011, que afecta también al artículo 168 LC, se centra en adaptar el texto para que concuerde con la nueva regulación de la reapertura de la sección de calificación del artículo 167.2, pero no soluciona los problemas de interpretación que habían ido surgiendo. Sin ninguna duda es ésta, como luego lo serían otras, una oportunidad malgastada por el legislador para poner en mejor concierto las normas procesales de la LC.

\subsubsection{Naturaleza y contenido del escrito de alegaciones del 168 LC}

La anterior discusión sobre la calidad del status procesal de los interesados es trascendental para delimitar el contenido del escrito de alegaciones. La naturaleza la posición procesal será determinante para entender si en el escrito de alegaciones del artículo 168 LC sólo cabe informar o si, por el contrario, este trámite encierra la formulación de una auténtica demanda.

20 A. MUÑOZ PAREDES, P. PRENDES, Tratado Judicial de la Insolvencia, Editorial Thompson Reuters. Tomo II, 2012. Citado en J. DE MIQUEL BERENGUER, La Pieza de Calificación en el Concurso de Acreedores, Bosch, Barcelona, 2012, pp. 35-36.

${ }^{21}$ C. ROSENDE VILLAR, "Comentario al artículo 168. Personación y condición de parte", Comentarios a la Ley Concursal (Dir. CORDÓN MORENO, F.), Tomo II, Editorial Aranzadi, Navarra, 2010, 2a Edición, p. 610.

22 S. FRAU I GAIÀ, La Calificación en el Concurso de Acreedores. Una visión crítica, Editorial Tirant lo Blanch, Valencia, 2014, P. 120. 
En definitiva, si se entendiera que estos acreedores e interesados no son parte plena, no se les permitirá sostener una calificación y solicitar la práctica de prueba, así como tampoco, llegado el momento, recurrir la sentencia de calificación o el auto que acuerde el archivo.

Aquí hemos de retomar el debate expuesto en el subapartado anterior, y traer a colación las decisiones de los tribunales, pues en esta materia se ha producido un intenso debate en el seno de los juzgados y audiencias, que llegó a elevarse al Tribunal Supremo. Veamos rápidamente algunos de los pronunciamientos judiciales más relevantes en la materia:

A) A favor de la plena intervención:

Fue una sentencia de la Audiencia Provincial de Alicante la que entendió que el argumento ya expuesto sobre la modificación en la rúbrica del artículo 168 era de capital importancia para determinar que los acreedores e interesados ostentan plenamente la condición de parte ${ }^{23}$ :

$<<$ Estimamos que esta circunstancia es de gran relevancia en la cuestión que analizamos. Si, bajo el imperio de la redacción originaria del referido precepto, la posición mayoritariamente mantenida por los diversos órganos judiciales de lo mercantil (AAP Barcelona, Sec. 15a, de 22-5- 2008, SSAAPP Jaén 13-4-2007, Murcia de 30-7-2009 o AJM no 1 de Coruña de 6-3-2008, entre otras muchas) era que los personados (por ser acreedores o por acreditar un interés legítimo) habían de ser considerados como "interesados" y no como parte ( $y$, por tanto, su actuación quedaba limitada a alegar por escrito cuanto consideraran relevante para la calificación del concurso como culpable), con la reforma citada, en cuanto se elimina la calificación de" interesados" y se atribuye, en la rúbrica y en el texto, a los personados la condición de "parte", habrá que afirmar que les corresponde, con el contenido procesal que le es inherente.

$O$, dicho de otra forma, si, con la nueva redacción se siguiera manteniendo que la única posibilidad de actuación de los acreedores personados es la de, simplemente, efectuar alegaciones por escrito de lo relevante para la calificación del concurso como culpable, la reforma carecería de sentido y utilidad. Si con la redacción anterior y con la nueva su papel fuera el mismo (relegado, en definitiva, a la mera formulación de alegaciones para coadyuvar a las auténticas partes actoras, administración concursal y Ministerio Fiscal), no se entiende la reforma producida.

La interpretación de que la atribución expresa de la condición de parte permite deducir pretensiones (lo cual es lo propio, en el sistema procesal civil español) es la única que da sentido (por utilidad) a la reforma

\footnotetext{
${ }^{23}$ Ésta fue la primera sentencia de una audiencia provincial que se pronunció en este sentido, aunque ya se había dictado alguna otra, v. gr. la Sentencia del Juzgado de la Mercantil núm. 1 de Alicante de 1 de septiembre de 2010.

La cita se ha extraído de la Sentencia de la Audiencia Provincial de Alicante 536/2012, de 20 de diciembre de 2012 (RA 364/2012), ponente: Francisco José Soriano Guzmán. Id. Cendoj: 03014370082012100538. Esta sentencia confirma íntegramente la del Juzgado de lo Mercantil núm. 1 de Alicante, de 11 de marzo de 2011, ponente: Rafael Fuentes Devesa.
} 
legislativa mencionada, pues, en caso contrario, no hubiera sido precisa, pues nada se añadía con ella>>.

B) En contra de la plena intervención:

Además de las resoluciones ya citadas, otras muchas se fueron dictando en este sentido. La doctrina judicial es resumida del siguiente modo:

$<<$ En definitiva, la sentencia de calificación no puede tener en cuenta las alegaciones de los acreedores y terceros con interés legítimo personados en la sección sexta con independencia y al margen del informe de la administración concursal o el dictamen del ministerio fiscal. Por el contrario, sólo en la medida en que las alegaciones y las causas de calificación invocadas por los acreedores y terceros con interés legítimo hayan sido asumidas por la administración concursal o el ministerio fiscal podrán ser tomadas en consideración para fundar la calificación culpable del concurso $>>24$.

$<<$ Por su parte los acreedores y otras personas con interés legítimo podrán personarse, pero sus escritos solo podrán hacer alegaciones en pos de la culpabilidad del concurso, adoptando una posición similar a la coadyuvante, pues no tendrán legitimación por si mismos para lograr una calificación culpable si la misma no es propuesta por alguna de las dos partes necesarias de la sección de calificación, la Administración Concursal y el M. Fiscal $>>^{25}$.

C) El criterio del Tribunal Supremo:

Debemos comenzar haciendo una referencia a las SSTS 534/2012, de 13 de septiembre, 608/2012, de 24 de octubre y 627/2012, de 30 de octubre. En todas estas sentencias, el Tribunal de apelación, por razones de fondo, desestimó el recurso de apelación de la Tesorería General de la Seguridad Social, que se había personado en la Sección Sexta del concurso, basando su decisión en la redacción primitiva del art. 168 de la Ley $22 / 2003$, de 9 de julio, antes de la modificación operada por el RDL 3/2009, -a cuyo tenor <<cualquier acreedor o persona que acredite interés legítimo podrá personarse en la sección alegando por escrito cuanto considere relevante para la calificación del concurso como culpable $>>$ y en la norma del apartado $1^{\circ}$ del art. 170 LC, según la que $<<$ si el informe de la administración concursal y el dictamen que, en su caso, hubiera emitido el Ministerio Fiscal coincidieran en calificar el concurso como fortuito, el Juez, sin más trámites, ordenará el archivo de las actuaciones mediante auto, contra el que no cabrá recurso alguno >>. Proseguía el Alto Tribunal razonando que la cuestión planteada tenía $<<$ un evidente fundamento procesal [...] pero también un contenido sustantivo, al defender la legitimación del derecho material, que es el que otorga o deniega la titularidad del derecho, obligación o interés discutido en el proceso $>>$.

24 Entre otras, Sentencia 170/2016, de 6 de mayo de 2016, de la Audiencia Provincial de Madrid, Sección 28 (RA 96/2016) ponente: ALBERTO ARRIBAS HERNANDEZ. Id Cendoj: 28079370282016100114.

${ }_{25}$ Sentencia 131/2016, de 21 de abril de 2016, del Juzgado de lo Mercantil de Girona, Sección $1^{a}$ (RA 302/2013), ponente Víctor Heredia del Real. Id. Cendoj: 17079470012016100208. 
Con base en aquellas sentencias, hubo quien consideró, enarbolando los motivos ya expuestos, que el Tribunal Supremo acogía en estas Sentencias la posibilidad de que los interesados pudieran formular no sólo el escrito de hechos relevantes, sino también sostener una calificación provisional, con efectos de petitum procesal.

Sin embargo, con posterioridad, el Tribunal Supremo aclaró en varias ocasiones su postura, que no es sino la contraria. Veamos dos de las resoluciones clave en el asunto:

(i) Sentencia del Tribunal Supremo de 3 de febrero de $2015^{26}:<<$ los acreedores y demás interesados en la calificación carecen de legitimación para pedir una determinada calificación, pero se les reconoce la posibilidad de intervenir como adyuvantes de la concreta petición de calificación formulada por la administración concursal y/o el ministerio fiscal, y para apelar (art. 172. bis. 4 LC). Y a estos concretos efectos se les reconoce la condición de parte>>.

(ii) Sentencia del Tribunal Supremo de 1 de abril de 2016 ${ }^{27}$ : $<</ a$ legitimación para pedir que se califique culpable el concurso, con los consiguientes pronunciamientos, corresponde exclusivamente a la administración concursal y al ministerio fiscal. Solo a ellos les corresponde emitir «propuestas de resolución», según lo previsto en los dos primeros apartados del art. 169 LC>>.

A mayores de lo expuesto no está de más citar el Auto del Pleno del Tribunal Constitucional 35/2016, de fecha 16 de febrero de $2016^{28}$, que se pronuncia obiter dicta acerca de la calidad de parte procesal de acreedores e interesados, y si puede considerarse inconstitucional la corriente jurisprudencial que les niega el carácter de parte plena de la sección sexta. Dice el Tribual Constitucional:

$<<$ Del examen de la regulación establecida en la Ley concursal, puede afirmarse que la limitación de la intervención del acreedor y de aquellos que ostentan un interés legítimo en la sección de calificación, se sustenta en la consideración de que los «intereses que se ejercitan en la sección de calificación no son estrictamente públicos, pues los hay generales del concurso y por ello de los acreedores en su conjunto» (STS 10/2015, de 3 de febrero), de tal modo que ha limitado la legitimación para ejercitar las acciones de calificación a la Administración concursal y al Ministerio Fiscal. La finalidad de dicha limitación, como ha tenido ocasión de señalar la citada STS 10/2015, es «evitar una acumulación de acciones particulares, encomendando a la Administración concursal y al Ministerio Fiscal el ejercicio de esta acción», pues a la Administración concursal le

\footnotetext{
${ }^{26}$ Sentencia del Tribunal Supremo 10/2015 de 3 de febrero de 2015 de la Sala de lo Civil, Sección: $1^{\text {a }}$ (RC 466/2013), ponente: SEBASTIAN SASTRE PAPIOL. Id Cendoj: 28079110012015100077.

27 Sentencia del Tribunal Supremo 203/2016, de 1 de abril de 2016, de la Sala de lo Civil, Sección $1^{\text {a }}$ (RC: 2616/2013) ponente: IGNACIO SANCHO GARGALLO. Id Cendoj: 28079110012016100199.

28 Auto mediante el cual inadmite a trámite la cuestión de inconstitucionalidad 6379/2014, planteada por el Juzgado de lo Mercantil núm. 1 de Oviedo respecto del artículo 168.1 LC.
} 
corresponde la representación de los intereses generales del concurso, dentro de los cuales se encuentran los de los acreedores concursales a obtener la íntegra satisfacción de sus créditos, y al Ministerio Fiscal la defensa del interés público $>>$.

D) Conclusión

La conclusión es clara: los acreedores e interesados ostentan en la pieza de calificación una condición de meros adyuvantes, con excepción de los trámites delimitados por la LC, en los que se les tendrá como partes. En efecto, pese a carecer de legitimación para pedir una determinada calificación, se les reconoce, entre otras, la posibilidad de formular alegaciones a los efectos de informar a la administración concursal, alegando lo que consideren relevante para la calificación del concurso como culpable (art. 168.1 LC), así como de intervenir como coadyuvantes de la concreta petición de calificación formulada por la Administración concursal y/o el Ministerio Fiscal, y también de interponer recurso de apelación (art. 172 bis. 4 LC). Y a estos concretos efectos se les reconoce la condición de parte.

Consecuentemente, el escrito de hechos relevantes del artículo 168 LC será solamente eso.

\subsection{Tramitación de la sección sexta}

Con la reforma aprobada en el año 2011, el legislador modificó sustancialmente el sistema inicialmente previsto respecto del papel de la administración concursal y del Ministerio Fiscal ${ }^{29}$. Éstos se configuran como órganos independientes, por cuanto la primera no defiende ni representa a los acreedores, ni al deudor, actuando sólo en aplicación de la ley y sometida al juez de lo mercantil, mientras que el segundo interviene en desarrollo de su principal función, que no es otra que la defensa de la legalidad.

En este apartado analizaremos el desarrollo de los trámites legales que sustancian el cauce por el que debe discurrir la sección sexta, una vez declarada abierta la pieza y personados acreedores e interesados, y hasta que el juez del concurso dicte la correspondiente sentencia de calificación, o decrete el archivo de las actuaciones de esta sección.

\subsubsection{Informe de la administración concursal: plazo}

Una vez personados los acreedores e interesados, habiendo alegado lo que fuera conveniente para la calificación del concurso como culpable, es el turno de la administración concursal para intervenir en la sección sexta, de acuerdo con el artículo 169.1 LC: <<Dentro de los quince días siguientes al de expiración de los plazos para personación de los interesados, la administración concursal presentará al juez un informe razonado y documentado sobre los hechos relevantes para la calificación del concurso, con propuesta de resolución >>.

29 M. A. DÍAZ GÓMEZ, C. MIGUÉLEZ DEL RÍO, "La Calificación del Concurso Tras la Reforma Introducida en la Ley Concursal por la Ley 38/2011", Revista Pecvnia, núm. 14, 2012, pp. 145-168. 
Para apreciar el dies a quo de este plazo de quince días debemos recordar que el artículo 168.1 LC, que establece a su vez el plazo para la personación de los acreedores e interesados es de diez días, a partir de la última publicación que se hubiera dado a la resolución que declara la apertura de la sección sexta.

Resulta imprescindible para la interpretación del artículo 169, con respecto al plazo del que dispone la administración concursal, atender a ciertas sentencias del Tribunal Supremo, que aportan una nueva jurisprudencia que trasciende la literalidad de la norma ${ }^{30}$.

En primer lugar, la Sentencia 122/2014, de 1 de abril de 2014, de la Sala Primera del TS (RC 541/2012), respecto del inicio del cómputo del plazo expone lo siguiente:

$<<$ Los plazos establecidos en los arts. 168.1 y 169.1, ambos de la Ley Concursal, están establecidos a diferentes efectos y dirigidos, por así decir, a distintas partes procesales, el primero a los acreedores y demás personas con interés legítimo para personarse en la sección de calificación, el segundo a la administración concursal. El órgano judicial debe constatar que el primer plazo ha transcurrido, una vez le conste cuándo ha tenido lugar la última publicación del auto que abre la fase de liquidación, debe dictar la resolución en la que se admitan o rechacen los escritos de personación y alegaciones presentados por los acreedores o interesados $y$, dando traslado de tales escritos, si son admitidos, puesto que pueden aportar información valiosa para el interés del concurso, debe otorgar el plazo de quince días a la administración concursal para que presente el informe de calificación $>>$.

El Tribunal, por lo tanto, se decanta por supeditar el inicio del cómputo del plazo a (i) que se haya dictado la resolución que admita o rechace los escritos de personación y alegaciones, y (ii) que se dé traslado de los escritos a la administración concursal. Esta interpretación elimina de facto el carácter automático del plazo previsto en el artículo 169.1 LC.

Dos son los motivos que llevan al Alto Tribunal a desviarse de la literalidad del precepto ${ }^{31}$. En primer lugar, el automatismo del plazo representa un grave obstáculo para la administración concursal por causa de su propia brevedad. Por otro lado, el automatismo genera una gran inseguridad jurídica, ya que sin una resolución judicial que avale el cómputo del mismo, será difícil para la administración concursal conocer el hecho que determina el inicio del cómputo, que a su vez depende de la fecha de la última publicación.

\footnotetext{
${ }^{30}$ De ambas fue ponente el Magistrado Rafael Sarazá Jimena.

31 Estima el Tribunal Supremo en dicha Sentencia que: <<una interpretación como la sostenida por la recurrente, según la cual el segundo plazo comienza a correr automáticamente cuando finaliza el primero, sin necesidad de actuación alguna del órgano judicial, generaría una gran inseguridad y supondría un obstáculo desproporcionado al ejercicio de la acción por parte de la administración concursal, habida cuenta de la brevedad de los plazos en cuestión y las dificultades de la administración concursal para conocer el hecho relevante para el cómputo del plazo de cuyo transcurso se hace depender el inicio a su vez del plazo que se le concede para formular el informe previsto en el art. 169.1 [...] >>.
} 
El primero de los argumentos es quizás menos solvente desde el punto de vista de la técnica jurídica, puesto que, en primer lugar, es el legislador quien fija el plazo oportuno para cada trámite, y, además, la duración más - menos extensa del plazo no faculta al juez para revisar el dies a quo establecido por ley. Por otro lado, el artículo 133.1.2 de la Ley de Enjuiciamiento Civil dispone que: <<cuando la Ley señale un plazo que comience a correr desde la finalización de otro, aquél se computará, sin necesidad de nueva notificación, desde el día siguiente al del vencimiento de éste $>>{ }^{32}$. El segundo argumento, relacionado con las dificultades de la administración concursal para conocer el inicio del cómputo del plazo, encuentra su justificación en la inseguridad jurídica que se produce en la práctica y para evitar, como sucedía en ocasiones, que la administración concursal aportara su informe antes incluso de que se hubiera dado inicio a su plazo 33 . A estos dos argumentos se le puede añadir que, como exponíamos respecto de la personación de los interesados, es fundamental que la administración concursal pueda formular su informe a la vista de lo expuesto por aquellos que tienen información trascendental para la calificación del concurso.

Cabe plantearse asimismo cuáles son las consecuencias del incumplimiento del plazo para presentar el informe de calificación. Para dar respuesta a dicha cuestión, la Sentencia de 5 de febrero de 2015, de la Sala Primera del Tribunal Supremo (RC 1086/2013) pondera inicialmente si el trámite de informe tiene carácter necesario dentro de la sección sexta. Para el Tribunal Supremo, es de capital importancia el carácter vinculante del informe, para el caso de que se califique como concurso fortuito. Considera que dicho trámite es esencial para el procedimiento, independientemente de la calificación que en él se contenga.

Expone la Sentencia que: <<el informe de la Administración Concursal previsto en el art. 169.1 de la Ley Concursal tiene el carácter de necesario, ya proponga que el concurso se califique como culpable, ya como fortuito. No ocurre lo mismo con el dictamen del Ministerio Fiscal (último inciso del art. 162 de la Ley Concursal ), ni con la oposición de la concursada o de las personas afectadas o cómplices en el caso de que la Administración Concursal o el Ministerio Fiscal postulen la calificación del concurso como culpable, pues si no comparecen se les declara en rebeldía (art. 170.3 de la Ley Concursa ), y si ninguno se opusiera a las peticiones

32 La disposición final $5^{a}$ LC contiene la cláusula general de remisión a la LEC, con referencia expresa al cómputo de los plazos: <<En lo no previsto en esta Ley será de aplicación lo dispuesto en la Ley de Enjuiciamiento Civil, y específicamente en lo que se refiere al cómputo de plazos determinados en la misma, así como en relación con la documentación de las actuaciones mediante sistemas de grabación y reproducción de la imagen y el sonido $>>$.

33 M. I. HUERTA VIESCA, D. RODRÍGUEZ RUIZ DE VILLA, "El plazo para la emisión del informe-demanda de calificación concursal del artículo 169.1 LC", Diario La Ley, No 8527, Sección Tribuna, 27 de Abril de 2015, Ref. D-159, Editorial LA LEY. Disponible en: http://www.juntadeandalucia.es/institutodeadministracionpublica/aplicaciones/boletin/pu blico/boletin65/Articulos_65/Rodriguez-Ruiz_Huerta-Viesca.pdf (Consultado 19.02.2018). 
de la Administración Concursal y el Ministerio Fiscal, se dictará sin más sentencia (art. 171.2 de la Ley Concursal)>>.

Siguiendo a lo expuesto, el Tribunal concluyó que: <<está justificado que en determinadas circunstancias, el Juez del concurso pueda posponer el inicio del plazo para formular el informe de la Administración Concursal (bien desde el primer momento, bien dejando sin efecto el trámite iniciado). Para ello es necesario que concurran circunstancias que lo justifiquen y que la posposición del inicio del plazo sea razonable >>.

En todo caso, hay que tener en cuenta que, a diferencia de la STS $122 / 2014$ (ampliamente seguida en la praxis procesal), este último pronunciamiento no constituye por el momento corriente jurisprudencial, y algunos autores todavía consideran que no cabe la posposición ${ }^{34}$.

\subsubsection{Informe de la administración concursal: contenido}

Refiriéndose al contenido de dicho informe, el artículo 169 dispone que debe ser "informado y documentado" y que contendrá una propuesta de calificación. Además, de acuerdo con dicho artículo, cuando la propuesta fuera de calificación culpable del concurso, el informe deberá aclarar necesariamente la identidad de las personas afectadas por la calificación, incluyendo a los cómplices. Deberá precisar los hechos relevantes que conducen su razonamiento hacia tal conclusión, así como la determinación de los eventuales daños y perjuicios causados a la masa activa del concurso, que serán objeto de indemnización.

En definitiva, lo que se espera de la administración concursal no es sino que exponga su visión acerca de las posibles responsabilidades en la generación o agravación del concurso, adelantando en cierto modo lo que será el pronunciamiento judicial, y por ello, su contenido guarda una estrecha relación con las menciones indispensables de la sentencia de calificación, expuestas en el artículo 172 y 172 bis LC.

De la redacción del artículo 169 se puede colegir la intención del legislador de que tanto el informe de la administración concursal como el dictamen del Ministerio Fiscal contengan los hechos relevantes para la calificación del concurso, así como el reconocimiento de los libros obligatorios y de la contabilidad del deudor y su contenido ${ }^{35}$.

Conviene poner de relieve el debate que ha suscitado el contenido y el alcance del informe de calificación de la administración concursal. La anterior LEC (1881) en su artículo 1.383 señalaba que los síndicos debían deducir "pretensión formal sobre la calificación de la quiebra". Ello no dejaba resquicio de duda: debían manifestar la calificación que debía ser aplicada a la quiebra en cuestión, y tal manifestación constituía su pretensión en el procedimiento ${ }^{36}$.

${ }^{34}$ J. DE MIQUEL BeRENGUER, La Pieza de Calificación en el Concurso de Acreedores, Bosch, Barcelona, 2012.

35 S. OLIVER BARCELÓ, "Comentario al art. 169 LC" en J. PULGAR EZQUERRA, C. ALONSO LEDESMA, A. ALONSO UREBA, G. ALCOCER GARAU, Comentarios a la Legislación Concursal, Registradores de España/Dykinson, Madrid, 2004, p. 1424.

${ }^{36}$ C. ROSENDE VILLAR, "Comentario al artículo 168. Personación y condición de parte", Comentarios a la Ley Concursal (Dir. CORDÓN MORENO, F.), Tomo II, Editorial Aranzadi, 
Ahora, siendo este informe, como se ha expuesto, un elemento esencial de la sección sexta, trasciende lo que sería una enunciación de la mera opinión acerca de las posibles responsabilidades a efectos de la calificación y de las razones que conducen tales valoraciones. Se echa en falta en la LC una mayor concreción de su contenido.

Muchos entienden que a pesar de que la ley utiliza la palabra "informe" (quizás en un intento de mantener la nomenclatura anterior), lo cierto es que se trata de una verdadera demanda, y debe cumplir los requisitos de la misma, lo que nos remite al artículo 399 de la LEC ${ }^{37}$. Existe una amplia jurisprudencia en este sentido, incluso del Tribunal Supremo ${ }^{38}$. Una Sentencia del Juzgado de lo Mercantil de Girona resume la postura de los tribunales de forma clara ${ }^{39}$ :

$<$ <entro de la dinámica procesal, el informe de la administración Concursal debe ser considerado como un verdadero escrito en que se ejercita la pretensión, que no solo debe calificar el concurso como culpable o fortuito, sino que tiene que especificar cuáles son los hechos por los que sostiene esta calificación, los fundamentos jurídicos de la misma y contener propuesta de resolución identificando a las personas que pueden resultar afectas por la calificación y las que pueden ser consideradas cómplices. Debiéndose tener presente, que es la administración concursal y el Ministerio Fiscal a través de sus informes de calificación, los que cuentan con poder dispositivo respecto del futuro de la pieza de calificación, en cuanto que solo podrá entrarse a valorar sobre la posible culpabilidad del concurso en el caso de que en alguno de estos escritos se proponga, no en el caso de que los dos postulen la calificación fortuita $>>$. En lo relacionado con los concretos pronunciamientos de este informedemanda, como lo llaman algunos, habremos de remitirnos a los artículos 172 y 172 bis, que se refieren al contenido de las sentencias de

Navarra, 2010, 2a Edición, p. 615.

${ }^{37}$ S. FRAU I GAIÀ, La Calificación en el Concurso de Acreedores. Una visión crítica, Tirant lo Blanch, Valencia, 2014, P. 123.

38 STS 301/2016, de 01.04.2016 (RC 2616/2013), ponente Ignacio Sancho Gargallo: $<<$ La Ley no sujeta el informe de la administración concursal, ni el dictamen del ministerio fiscal, a una formalidad específica. Pero como deben contener una solicitud concreta y las razones que justifican esta petición, que lógicamente se fundarán en una relación de hechos y en su valoración jurídica, la forma es equivalente a la demanda. Deben contener una propuesta clara de resolución ( art. 169.1 LC ), lo que permite relacionar estos escritos de alegaciones con la sentencia de calificación, pues ha de pedirse, en primer lugar, una calificación fortuita o culpable, y, en este segundo caso, lo que pretenden que recoja la sentencia de calificación culpable del concurso, conforme a los pronunciamiento previstos en el art. 172 (tras la Ley 38/2011, también el art. 172 bis LC ): personas afectadas por la calificación culpable $y$, en su caso, los cómplices; tiempo de inhabilitación; pérdida de derechos en el concurso, obligación de restituir lo indebidamente percibido, indemnización de daños y perjuicios ocasionados por las conductas que motivan la calificación culpable, y la posible condena a los administradores (o liquidadores) para indemnizar el importe total o parcial de los créditos no satisfechos con la liquidación (actualmente, cobertura del déficit concursal)>>.

39 Sentencia 131/2016, de 21 de abril de 2016, del Juzgado de lo Mercantil de Girona, Sección $1^{a}$ (RC 302/2013), ponente Víctor Heredia del Real. Id. Cendoj: 17079470012016100208. 
calificación. Por otro lado, es éste el momento oportuno para la proposición de la prueba de la que pretenda valerse la administración concursal, aunque no esté previsto expresamente ${ }^{40}$.

La posibilidad de pedir medidas cautelares no encuentra en la sección sexta ningún límite específico que nos obligue a apartarnos de lo dispuesto en el artículo 48 ter LC para el embargo de bienes. En cualquier momento, una vez formada la sección de calificación, podrá la administración concursal instar el embargo de los bienes y derechos de administradores y liquidadores, tanto de hecho como de derecho, apoderados generales y de todos aquellos que ostentaran estos cargos dentro de los dos años anteriores a la declaración del concurso ${ }^{41}$. Cabe señalar asimismo que la disposición excluye, por su carácter generalista, la mención a los cómplices, que son sujetos cuyas apariciones se limitan al ámbito de la pieza de calificación. Por ello estimo que será muy difícil mantener que un eventual cómplice (que nunca podrá ser uno de los sujetos antes descritos) pueda ser sometido al embargo previo a la resolución que lo condene a abonar daños y perjuicios.

\subsubsection{Dictamen del Ministerio Fiscal}

El artículo 169.2 de la LC dispone que una vez unido el informe de la administración concursal a los autos de la sección sexta, el Letrado de la Administración de Justicia dará traslado del contenido de la sección sexta al Ministerio Fiscal para que emita dictamen en el plazo de diez días. Añade posteriormente que si el Ministerio Fiscal no emitiera dictamen en ese plazo, seguirá su curso el proceso y se entenderá que no se opone a la propuesta de calificación.

\footnotetext{
${ }^{40}$ Este tema se desarrolla en el apartado 3.3.6 sobre la oposición del demandado.

${ }^{41}$ Estimamos, pues, que el contenido del artículo 48 ter es perfectamente aplicable en el ámbito de la sección sexta, para lo cual habrá que interpretar la literalidad del precepto mutatis mutandis. El artículo 48 ter LC dispone:

$<<1$. Desde la declaración de concurso de persona jurídica, el juez del concurso, de oficio o a solicitud razonada de la administración concursal, podrá acordar, como medida cautelar, el embargo de bienes y derechos de sus administradores o liquidadores, de hecho y de derecho, apoderados generales y de quienes hubieran tenido esta condición dentro de los dos años anteriores a la fecha de aquella declaración, cuando de lo actuado resulte fundada la posibilidad de que en la sentencia de calificación las personas a las que afecte el embargo sean condenadas a la cobertura del déficit resultante de la liquidación en los términos previstos en esta ley.

El embargo se acordará por la cuantía que el juez estime y podrá ser sustituido, a solicitud del interesado, por aval de entidad de crédito.

2. De igual manera, durante la tramitación del concurso de la sociedad, el juez, de oficio o a solicitud razonada de la administración concursal, podrá ordenar el embargo de bienes y derechos del socio o socios personalmente responsables por las deudas de la sociedad anteriores a la declaración de concurso, en la cuantía que estime bastante, cuando de lo actuado resulte fundada la posibilidad de que la masa activa sea insuficiente para satisfacer todas las deudas, pudiendo, a solicitud del interesado, acordarse la sustitución del embargo por aval de entidad de crédito.
}

3. Contra el auto que resuelva sobre la medida cautelar cabrá recurso de apelación >>. 
También se contempla la posibilidad de que se acuerde, si concurren circunstancias que lo justifiquen, la prórroga de dicho plazo por un máximo de diez días más.

Como puede apreciarse, aun cuando la Exposición de Motivos de la LC contempla la participación del Ministerio Fiscal como parte en la sección sexta, la única función que le atribuye el precepto es la presentar un dictamen, cuya carencia no impide el subsiguiente desarrollo del proceso. Tampoco quiere decir esto que el juez del concurso no esté obligado a pedirlo (que lo está), ni que el Ministerio Fiscal pueda elegir si interviene o $\mathrm{no}^{42}$.

En este sentido, si la omisión del dictamen ha de entenderse como favorable a la calificación realizada por la administración concursal, no podemos considerar dicha intervención como trámite esencial del procedimiento (como sí lo es la informe de la administración concursal), lo que por otro lado tampoco parece limitar la posibilidad de que el Ministerio Fiscal recurra la sentencia de calificación. Sin embargo, en este supuesto, en el que aceptó tácitamente la calificación propuesta en el informe de administración concursal, si el juez dicta sentencia de conformidad con el informe-demanda de la administración concursal entendemos que no podrá variar su calificación y recurrir en base a la nueva, pues entraría en vigor la prohibición de la mutatio libelli ${ }^{43}$.

En lo referente al contenido del dictamen del Ministerio Fiscal nos remitimos a la jurisprudencia citada en el subapartado anterior, relativa al informe de la administración concursal. Huelga decir que el contenido de este dictamen es completamente autónomo respecto del informe de la administración concursal, pudiendo el Ministerio Fiscal coincidir con éste en todo, solamente en algunas cuestiones, o en nada.

Es perfectamente posible, en mi opinión, que el Ministerio Fiscal solicite la adopción de las medidas cautelares del artículo 48 ter LC. Aunque el artículo 48 ter se refiere solamente a medidas adoptadas de oficio o a solicitud razonada de la administración concursal, no existe óbice a que el Ministerio Fiscal reclame del juez la adopción de tales medidas de oficio por parte del juez, por mucho que su instancia no pueda considerarse una verdadera solicitud a efectos procesales ${ }^{44}$. Esto es aplicable, considero,

\footnotetext{
42 Desde luego es cuando menos curioso percatarse de que ciertas partes en la sección los acreedores e interesados (que no son verdaderas partes) tienen esa condición sólo para evacuar un par de trámites, mientras que una parte verdadera, como quiere configurarse al Ministerio Fiscal, tenga una sola intervención, obligada, y ni siquiera sea estrictamente necesario su dictamen.

43 Pensemos, por ejemplo, en el absurdo que se produciría si la Fiscalía reputara culpables a otros sujetos de los que tuvieron ocasión de oponerse, o en base a una presunción legal sobre la cual no versó la prueba celebrada en la vista del trámite de oposición.

${ }^{44}$ Es reseñable, asimismo, que al Ministerio Fiscal le ha sido conferida una importante participación en las medidas provisionales que exceden las puramente civiles. Así, la Ley Orgánica 8/2003, de 9 de julio, para la Reforma Concursal, por la que se modifica la Ley Orgánica 6/1985, de 1 de julio, del Poder Judicial, en su artículo 1 , recoge que para la adopción de determinadas medidas de índole personal respecto del deudor persona física
} 
también a los interesados en el procedimiento, incluso aunque la jurisprudencia les haya cercenado la capacidad de sostener pretensiones de culpabilidad.

\subsubsection{Vinculación del juez a la calificación conjunta de concurso fortuito}

El juez debe atenerse necesariamente a lo propuesto en el informedemanda de la administración concursal y el dictamen del Ministerio Fiscal, en el caso de que ambos califiquen el concurso como fortuito, merced al artículo 170 LC. Cuando esto ocurra, dictará simplemente un auto de archivo de las actuaciones, que no será recurrible. Algunos interpretan este artículo como una introducción mutatis mutandis del principio acusatorio que rige en el proceso penal, y que implica que, sin parte alguna que sostenga la acusación, no es posible la apertura del juicio oral, ni mucho menos la condena ${ }^{45}$.

Queda fuera de las facultades del juez, como hemos visto, proseguir el procedimiento basándose sólo en una calificación de culpabilidad sostenida exclusivamente por acreedores o interesados, lo que les confiere a éstos una posición procesal anómala, habida cuenta de que sí podrán recurrir la sentencia que declare el concurso como fortuito (artículo 172 bis.4 LC). Como señala YANES $^{46}$, el auto que archiva las actuaciones no califica expresamente el concurso $y$, en esos casos, el concurso no llega a declararse fortuito sino que, comoquiera que no hay pretensión de culpabilidad, se archivan las actuaciones de la sección. Este archivo no tiene porqué ser definitivo, ya que es posible que la sección sea reabierta posteriormente por la resolución que apruebe la liquidación, si hay un incumplimiento de convenio ${ }^{47}$. En consecuencia, si se reabre la sección, no constará en los autos ningún pronunciamiento judicial sobre la calificación.

\subsubsection{Calificación provisional de culpabilidad}

En caso distinto al anteriormente expuesto, es decir, que sólo una de las partes se incline por la calificación fortuita, o ambas partes por la culpable, el juez deberá en primer término conceder audiencia al deudor en el plazo de diez días. Además, ordenará emplazar a todas las personas que, según resulte de lo actuado, pudieran ser afectadas por la calificación del concurso o declaradas cómplices, a fin de que, en plazo de cinco días, comparezcan en la sección si no lo hubieran hecho con anterioridad ${ }^{48}$.

y de los administradores y análogos, deberá acordarse audiencia previa con el Ministerio Fiscal.

${ }^{45}$ C. ROSENDE VILLAR, "Comentario al artículo 168. Personación y condición de parte", Comentarios a la Ley Concursal (Dir. CORDÓN MORENO, F.), Tomo II, Editorial Aranzadi, Navarra, 2010, 2a Edición, p. 621.

46 P. YANES YANES, "La Calificación Concursal", en VVAA; El Concurso de Acreedores (Dir. PULGAR IZQUERDO, J.), La Ley, Madrid, 2012.

47 A la reapertura de la sección sexta nos referimos ex profeso en el Capítulo 4.

${ }^{48}$ Con anterioridad a la Ley $22 / 2003$, concursal, no se preveía expresamente otorgar un trámite de alegaciones a los que pudieran ser declarados cómplices, lo que representaba una brecha inexcusable del derecho de audiencia y defensa de éstos. En la práctica, la 
Como se puede apreciar, el procedimiento desde la posición del deudor es sensiblemente diferente al previsto para los posibles afectados. Al deudor se le confiere un plazo de audiencia, mientras que a los sujetos potencialmente afectados se les concede un plazo de comparecencia, puesto que es posible que no todos hayan participado en la sección en calidad de interesados. Una vez comparecidos, el artículo 170.3 LC dispone que $:<<e l$ Secretario judicial les dará vista del contenido de la sección para que, dentro de los diez días siguientes, aleguen cuanto convenga a su derecho>>.

No se recoge en la ley con mayor precisión la manera de que éstos obtengan conocimiento de lo actuado una vez comparecidos. Lo más oportuno sería darles traslado de una copia completa de los autos de la sección, para que puedan preparar sus alegaciones con mayor tranquilidad $^{49}$. Además, este artículo contiene un segundo plazo para los posibles afectados que han comparecido: un plazo de alegaciones. Esta previsión es fundamental en aras a garantizar el derecho de defensa de aquellos sobre los que puede recaer responsabilidad en el concurso, bien a título de autores o bien de cómplices.

En caso de que estos sujetos no comparezcan en plazo se les declarará en rebeldía y las actuaciones seguirán su curso sin que vuelvan a ser emplazados ${ }^{50}$. El régimen aplicable a la rebeldía es el previsto en la LEC, al no recoger normas específicas la LC.

En caso de que no comparezcan en el plazo fijado de cinco días, y sí comparezcan en un momento posterior al plazo establecido, pero antes de que los hayan declarado en rebeldía, el juez les tendrá por parte, pero no retrocederá el curso de las actuaciones.

Si todos los sujetos potencialmente afectados ya se habían personado en su día como interesados, entiendo que el juez deberá otorgarles, sin mayor trámite, el plazo de alegaciones de cinco días, siempre y cuando les hubieran notificado los escritos de informe-demanda y dictamen. De lo contrario, sólo podrá comenzar el cómputo del plazo de alegaciones de diez días una vez sea puesto el expediente judicial a su disposición.

Otra nota relevante que cabe introducir es que la disposición se refiere a la obligación del juzgado de emplazar a todos aquellos que, "según resulte de lo actuado" puedan resultar afectados por la calificación, incluyendo a los cómplices. Esta expresión habremos de entenderla como una remisión

tramitación de la pieza quinta de la quiebra era conjunta respecto de la declaración de quiebra fraudulenta y de las conductas constitutivas de complicidad, un proceder amparado por la jurisprudencia del Tribunal Supremo en las Sentencias de 26 de mayo de 1972, 16 de julio de1991, entre otras.

${ }^{49}$ ROSENDE entiende, en este sentido, que la expresión "se les dará vista del contenido de la sección", unido a la distinción entre comparecencia y alegaciones favorece una interpretación en el sentido de permitir el traslado de las copias. C. ROSENDE VILLAR, "Comentario al artículo 168. Personación y condición de parte", VVAA Comentarios a la Ley Concursal (Dir. CORDÓN MORENO, F.), Tomo II, Editorial Aranzadi, Navarra, 2010, 2a Edición, pp. 623-624.

${ }^{50}$ Cabe destacar que la rebeldía sólo podrá declararse respecto de los posibles afectados, y no del deudor, a quien la LC tiene por comparecido en todo momento en la sección sexta. 
a los escritos de calificación provisional: el informe-demanda de la administración concursal y el dictamen del Ministerio Fiscal. Los sujetos que serán llamados a intervenir serán aquellos que las partes demandantes estimen responsables en sus escritos.

\subsubsection{Oposición a la calificación}

En su trámite de alegaciones del artículo 170 LC los sujetos potencialmente afectados pueden optar por una de estas tres alternativas: (i) plantear oposición a la calificación culpable que se cierne sobre ellos, continuando entonces el proceso por los cauces del incidente concursal; (ii) allanarse a la calificación provisional de alguna de las partes demandantes, o, simplemente, (iii) no oponerse a la calificación.

Comenzando por la última de las opciones, el artículo 171.2 LC dispone al respecto: < <Si no se hubiere formulado oposición, el juez dictará sentencia en el plazo de cinco días $>>$. No enuncia la ley de forma expresa si la falta de oposición obliga al juez a adoptar íntegramente bien las pretensiones de la administración concursal o bien las del Ministerio Fiscal, o si, por el contrario, la falta de pretensiones de la defensa faculta al juez para sustituir la oposición del demandado por los razonamientos producto de su propio criterio, sin estar ligado a las calificaciones provisionales.

Es necesario destacar que con anterioridad a la presente LC, la LEC 1881, en su artículo 1384 contemplaba que el juez en tales casos haría la calificación que estimara arreglada a derecho según lo que resulte de los autos. A esto se añade que, no habiendo un pronunciamiento expreso, estimamos que la falta de comparecencia no puede suponer, sin norma legal que lo ampare, una asunción de los hechos que se le imputan o una condena automática.

Por otro lado, sí podrá hacer uso la defensa de sus facultades dispositivas del proceso para allanarse, teniendo el juez que admitir la calificación conjunta de los hechos y dictando en ese caso sentencia condenatoria, con los necesarios pronunciamientos de la ley, a excepción de que el juez apreciara la concurrencia de fraude de ley o supusiera renuncia contra el interés general o perjuicio de tercero, en cuyo caso se rechazará mediante auto, ex artículo 21 LEC. En estos casos también deberá dictar sentencia en el plazo de cinco días, puesto que al allanarse totalmente, el demandado no formula ya oposición. Si el allanamiento es parcial, se podrá dictar auto acogiendo las pretensiones del mismo, y continuándose el procedimiento para las demás cuestiones o personas no allanadas ${ }^{51}$.

Retomemos ahora la primera de las opciones esbozadas: la oposición total del demandado. Según el artículo 171.1 LC: $<<$ Si el deudor o alguno de los comparecidos formulase oposición, se sustanciará por los trámites del incidente concursal. De ser varias las oposiciones, se sustanciarán juntas en el mismo incidente>>. La remisión en tales términos a los cauces del incidente concursal, como veremos, no es feliz.

${ }^{51}$ C. ROSENDE VILLAR, "Comentario al artículo 168. Personación y condición de parte", VVAA Comentarios a la Ley Concursal (Dir. CORDÓN MORENO, F.), Tomo II, Editorial Aranzadi, Navarra, 2010, 2a Edición, pp. 627-628. 
El incidente concursal es la nomenclatura que recibe el conjunto de normas procedimentales a las que la LC recurre para todas aquellas cuestiones que "se susciten durante el concurso y no tengan señalada en esta Ley otra tramitación" ${ }^{\prime 52}$. El artículo 194 LC contiene la regulación de este procedimiento, que deberá ser conjugada con la de la sección sexta ${ }^{53}$.

En primer lugar, debe prescindirse del trámite de la demanda y contestación previsto en al artículo 194 LC. En puridad, como ya se ha comentado, los escritos de demanda son el informe de la administración concursal y dictamen del Ministerio Fiscal, y éstos ya han debido ser presentados. Por su parte, la contestación a la demanda no es sino el escrito de alegaciones del deudor y los posibles afectados por la calificación. Esto contribuye a señalar a tales escritos como el momento procesal oportuno para aportar prueba documental y proponer asimismo otras pruebas que vaya a ser practicadas en la vista.

Efectivamente, el artículo prevé la celebración de una vista, que se celebrará de acuerdo con las normas del juicio verbal del artículo 443 de la LEC, siempre y cuando "exista discusión sobre los hechos y éstos sean relevantes a juicio del juez, y se hayan propuesto en los escritos de alegaciones medios de prueba, previa la declaración de su pertinencia y

\footnotetext{
52 cfr. artículos 192 a 196 LC.

53 Resulta imprescindible la lectura del artículo para comprender los problemas que plantea la remisión del artículo 171 LC: <<Artículo 194. Demanda incidental y admisión a trámite.
}

1. La demanda se presentará en la forma prevista en el artículo 399 de la Ley de Enjuiciamiento Civil.

2. Si el Juez estima que la cuestión planteada es impertinente o carece de entidad necesaria para tramitarla por la vía incidental, resolverá, mediante auto, su inadmisión y acordará que se dé a la cuestión planteada la tramitación que corresponda. Contra este auto cabrá recurso de apelación en los términos establecidos en el apartado 1 del artículo 197.

3. En otro caso, dictará providencia admitiendo a trámite el incidente y acordando se emplace a las demás partes personadas, con entrega de copia de la demanda o demandas, para que en el plazo común de 10 días contesten en la forma prevenida en el artículo 405 de la Ley de Enjuiciamiento Civil.

4. Sólo se citará a las partes para la vista cuando se haya presentado escrito de contestación a la demanda, exista discusión sobre los hechos y éstos sean relevantes a juicio del juez, y se hayan propuesto en los escritos de alegaciones medios de prueba, previa la declaración de su pertinencia y utilidad. Esta vista se desarrollará en la forma prevista en el artículo 443 de la Ley de Enjuiciamiento Civil para los juicios verbales.

En otro caso, el juez dictará sentencia sin más trámites. Lo mismo hará cuando la única prueba que resulte admitida sea la de documentos, y éstos ya se hubieran aportado al proceso sin resultar impugnados, o cuando sólo se hayan aportado informes periciales, y ni las partes ni el juez soliciten la presencia de los peritos en el juicio para la ratificación de su informe.

En cualquiera de los supuestos previstos en el párrafo anterior, si en el escrito de contestación se plantearan cuestiones procesales o se suscitaran por el demandante a la vista de este escrito en el plazo de cinco días desde que se le dio traslado del mismo, el juez las resolverá dictando la resolución que proceda conforme a lo dispuesto en la Ley de Enjuiciamiento Civil para la resolución escrita de este tipo de cuestiones conforme a lo previsto en la audiencia previa del juicio ordinario. Si la decisión fuera la de continuar el proceso, dictará sentencia en el plazo de diez días >>. 
utilidad". La necesidad de valorar con carácter previo a la vista la pertinencia y utilidad de las pruebas propuestas conduce a la celebración de una especie de audiencia previa escrita para fijar la prueba pertinente ${ }^{54}$.

Consideramos que el juez, en estos casos, tiene obligación de dictar sentencia, sin que resulten de aplicación las limitaciones referidas a la cuestión impertinente o de insuficiente entidad, prevista en el artículo 194.2 LC. Además, muchos autores razonan que debe ser celebrada la vista indefectiblemente, aun en caso de que no quede constancia de la pertinencia de la prueba propuesta ${ }^{55}$. Me inclino por la solución propuesta por RODRIGUEZ ACHÚTEGUI ${ }^{56}$, que según la cual no cabe pretender la celebración de la vista si no se propone prueba alguna, ya que la norma es clara al exigir la petición de parte y la declaración de pertinencia de la prueba instada. Con todo, prefiere confiar en que los tribunales, haciendo gala de buen criterio, decidan celebrar vista respecto de cuestiones complejas o novedosas, para que las partes puedan desarrollar su argumentación.

Otra cuestión que se puede suscitar es si cabe, después de la práctica de la prueba, introducir un trámite de conclusiones. Al igual que lo dicho acerca de la posibilidad de solicitar medidas cautelares en el marco de esta sección, no encontramos impedimento legal alguno para el juez acuerde introducir un trámite de conclusiones. Este trámite resultará muy atractivo en aquellos concursos que presenten gran complejidad, pues se ofrecerá a las partes una nueva posibilidad de desarrollar el fundamento de sus pretensiones en conexión con la valoración de la prueba practicada. Estimamos que el juez deberá, para garantizar el derecho de defensa, convocar este trámite especialmente cuando por la administración concursal o el Ministerio Fiscal se solicite la condena de inhabilitación, cuya naturaleza, entendemos, es la de una verdadera sanción.

\section{SENTENCIA DE CALIFICACIÓN, RECURSOS Y EJECUCIÓN}

La sección sexta tiene como premisa fundamental la determinación de las eventuales responsabilidades de quienes estuvieron al cargo del negocio $y$, en general, de quien tuvo una amplia capacidad de disposición sobre éste. La responsabilidad será predicada de ellos en función de si, con sus actos dolosos o culpables avocaron a la sociedad a la situación de insolvencia, o también si agravaron esa situación cuando era ya inevitable. También es posible, como se ha ido adelantando a lo largo del trabajo, que la culpabilidad del concurso se predique con arreglo determinadas presunciones legales, bien demostrando la concurrencia de las iuris et de iure, bien acreditando que las iuris tantum concurren y no son refutadas por prueba en contrario que pueda quebrar la conexión

\footnotetext{
${ }^{54}$ B. GONZÁLEZ NAVARRO, "Los aspectos procesales más relevantes de la reforma de la Ley Concursal abril 2009", Revista Aranzadi Doctrinal, núm. 4/2009 (BIB 2009, 686).

${ }^{5}$ DE MIQUEL BERENGUER y ROSENDE VILLAR entre otros, op. cit.

56 E. RODRIGUEZ ACHÚTEGUI, "Reformas Procesales del RDley 3/2009 en la Ley Concursal", Revista Aranzadi Doctrinal, núm. 5/2009 (BIB 2009, 686).
} 
entre la conducta que activa la presunción y el resultado producido (causar o agravar la insolvencia).

Este juicio de existencia de culpabilidad se lleva a cabo en la sentencia de calificación, resolución que pone fin a la sección sexta, si es que su final no ha sido anticipado por una calificación provisional conjunta de concurso fortuito. Pero también le corresponde a la sentencia determinar las consecuencias del concurso calificado como culpable. En la versión actual de la Ley Concursal, dos son los artículos que regulan la sentencia de calificación: el artículo 172 y el 172 bis, que anteriormente formaban una unidad. Ambos tienen una importancia capital, tanto desde el punto de vista procesal, pues representan el culmen de la tramitación de la sección sexta, como desde el punto de vista material, en tanto contienen la regulación de las consecuencias de la calificación culpable ${ }^{57}$.

A las cuestiones de los recursos contra la sentencia de calificación y su ejecución se refiere, curiosamente, el propio artículo 172 bis LC. Es llamativa la elección hecha por el legislador de incluir estas disposiciones en un artículo que versa sobre la responsabilidad concursal, presentando una vez más preceptos procesales entremezclados con los materiales.

En primer lugar, este artículo dispone que la ejecución de la sentencia de calificación debe ser instada por la administración concursal, quien, según parece, es la única parte que ostenta legitimación para ello. Los acreedores que pretendan la ejecución de la sentencia deberán, en primer término, acudir a la administración concursal, solicitando por escrito su intercesión ante el juez. Si la administración concursal no traslada la solicitud de ejecución al juez dentro del mes siguiente al requerimiento, aquéllos adquirirán legitimación para solicitarla del juez directamente por imperio del artículo 172 bis. 2 LC.

Queda la pregunta de qué ocurre con el Ministerio Fiscal, que no aparece nombrado en el artículo. En vista de que tiene en la sección sexta el mismo status de parte plena del procedimiento, entiendo que nada obstaría a que se dirigiera al juez del concurso directamente para reclamar la ejecución de la sentencia.

En relación con los recursos que caben contra la sentencia de calificación, solamente se recoge lo siguiente en el artículo 172 bis, apartado 4: $<<$ Quienes hubieran sido parte en la sección de calificación podrán interponer contra la sentencia recurso de apelación $>>$. Se le reconoce, por tanto legitimación para recurrir en apelación (recurso del cual conocerá la Audiencia Provincial correspondiente), a los siguientes sujetos: deudor, administración concursal, Ministerio Fiscal, sujetos afectados por la calificación, sujetos declarados cómplices, acreedores y demás interesados en la sección sexta, siempre y cuando hayan comparecido y presentado escrito de hechos relevantes. Resulta, por demás, digno de mención, que a ninguno de estos sujetos, ni siquiera a

\footnotetext{
57 Pese a ello, dichos artículos, en tanto regulan el contenido de la sentencia de calificación y no están exentos de vocación material, quedan excluidos del presente estudio, más enfocado a clarificar los trámites procesales de la sección sexta. Dejaremos el análisis, por tanto, para otra ocasión.
} 
los acreedores e interesados que pretenden una calificación culpable se les permita recurrir el auto que decreta el archivo de la sección sexta cuando existe calificación provisional conjunta de concurso fortuito.

Una vez resuelto el recurso de apelación, a tenor de lo dispuesto por el artículo 194.7 de la LC, cabrá recurso de casación y extraordinario por infracción procesal contra las sentencias dictadas por las audiencias relativas a la calificación del concurso, y cuya admisión estará siempre sometida a las reglas previstas en los artículos 467 a 469 de la LEC para segundo y 477.2 para el primero de ellos.

\section{INCUMPLIMIENTO DEL CONVENIO Y REAPERTURA DE LA SECCIÓN SEXTA}

Cerraremos la exposición con un comentario ad hoc sobre el tema, tremendamente notable, del tratamiento procesal de la llamada reapertura de la sección sexta y de las nociones de incumplimiento del convenio frente al fracaso del convenio, repasando como hasta ahora las deficiencias más relevantes de la Ley Concursal, y examinando las posibles soluciones.

Si el lector ha ido examinando la LC al tiempo que el desarrollo del Capítulo 2, habrá notado que he omitido todas las referencias que hace la ley a la reapertura y cuasi reapertura de la sección sexta. No me ha llevado a ello un descuido, sino más bien un afán de sistematizar las referencias a estas figuras, para poder presentarlas de un modo menos fragmentado y detenerme en ellas para realizar un análisis pormenorizado.

El concepto de reapertura de la sección de calificación va ligado indefectiblemente al incumplimiento de un convenio no gravoso ${ }^{58}$. Se habla de reapertura porque, si recordamos lo expuesto al principio del Capítulo 2, la resolución que apruebe el convenio debe asimismo declarar la apertura de la sección sexta, por lo que, si el incumplimiento del convenio puede generar una calificación culpable del concurso, ésta deberá ventilarse por separado.

Se prevén, en tal contexto, dos situaciones diferenciadas. En la primera, recogida en el artículo 167.2.1, ya se ha dado cierre a la sección de calificación que fuera iniciada en un primer momento, por lo que, cuando el juez resuelve liquidar, podrá resucitar la sección clausurada, con la particularidades que veremos. En el segundo escenario, sobreviene el incumplimiento del convenio cuando no ha sido resuelta todavía la sección de calificación. En este último caso, el artículo 167.2.2 dispone que deberá abrirse una pieza separada dentro de la sección en trámite.

Como recoge la una sentencia de la Audiencia Provincial de Barcelona ${ }^{59}$, el deudor tiene el deber de instar la liquidación cuando, en la vigencia del

\footnotetext{
$58 \mathrm{Si}$ el convenio incumplido no fuera gravoso, no estaríamos hablando de reapertura puesto que no habría sido abierta la sección sexta junto con la resolución que en su día aprobó tal convenio, de acuerdo con la excepción del artículo 167.1.II LC. Existiría en tal caso una primera apertura, que se formalizaría junto con la resolución que apruebe bien el plan de liquidación, bien la liquidación según las normas supletorias.

59 SAP Barcelona secc. $15^{a}$ de 26 de marzo de 2008 (RA 343/07).
} 
incumplimiento del convenio, conozca la imposibilidad de cumplir los pagos estipulados de las deudas concursales anteriores al convenio y las obligaciones contraídas con posterioridad a la aprobación de aquel. Es decir, cuando el propio deudor conozca "la imposibilidad de cumplir los pagos comprometidos y las obligaciones contraídas con posterioridad a la aprobación de aquél" (artículo 142.2 LC), lo que no es sino una referencia a la obligación de pedir la liquidación cuando se ha caído de nuevo en el estado de insolvencia previsto en el artículo 2.2 de la LC. En tal caso, en efecto, el Juez debe sin más abrir la liquidación, del mismo modo que al declarar el concurso voluntario.

Por otro lado, es posible que la liquidación se abra a instancias de los acreedores, pues es ésta una de sus facultades, aunque en tal caso el juez no resuelve automáticamente, sino que la liquidación será practicada solamente si el acreedor puede acreditar la existencia de alguno de los hechos que son susceptibles de provocar una declaración de concurso según lo dispuesto en el artículo 2.4 LC. Se dará a la solicitud el trámite previsto en los artículos 15 y 19 LC y resolverá el juez mediante auto si procede o no abrir la liquidación ${ }^{60}$.

También faculta la LC al juez para abrir de oficio la liquidación de la concursada, en virtud del artículo 143.1: <<Procederá de oficio la apertura de la fase de liquidación en los siguientes casos: [...] 5. o Haberse declarado por resolución judicial firme el incumplimiento del convenio $>>$.

Tanto si la liquidación es instada por el deudor, como si lo es por alguno de los acreedores o es declarada de oficio, la resolución que declare su apertura reabrirá simultáneamente la sección sexta (o pieza separada dentro de ésta). Como hemos visto esto será aplicable al incumplimiento de convenios gravosos, con una quita superior al tercio de los créditos o una espera superior a tres años. En lo relativo a los convenios no gravosos, que no cumplen tales requisitos, lo decretado por el juez será simplemente la "apertura" de la sección sexta, que no procedía en el momento de aprobación del convenio, por causa de su naturaleza no gravosa.

No existe duplicidad ni conculcación del principio non bis in ídem, puesto que la reapertura de la sección sexta, o la apertura de una pieza separa dentro de ésta, tiene por objeto el enjuiciamiento no de la responsabilidad respecto del concurso, sino de las causas que condujeron a la liquidación, es decir, al fracaso del convenio ${ }^{61}$. La idea del fracaso del convenio a la que se refiere el magistrado GONZÁLEZ NAVARRO es tremendamente relevante, pues pone de manifiesto otro error del legislador en la regulación de la sección sexta ${ }^{62}$.

\footnotetext{
${ }^{60}$ cfr. artículo 142.2.II de la Ley Concursal.

${ }^{61}$ En este sentido, el artículo 172 bis LC establece en su primer apartado que: <<si el concurso hubiera sido ya calificado como culpable, en caso de reapertura de la sección sexta por incumplimiento del convenio, el juez atenderá para fijar la condena al déficit del concurso tanto a los hechos declarados probados en la sentencia de calificación como a los determinantes de la reapertura>>.

62 B. A. GONZÁLEZ NAVARRO, La Calificación por Incumplimiento Sobrevenido del Convenio Concursal Especialmente Gravoso, Cuatrecasas, p. 4. Disponible en:
} 
Esta noción del fracaso del convenio incluye los dos escenarios (negativos) que pueden tener lugar tras la aprobación del convenio: el primero es el de la insolvencia sobrevenida (o reinsolvencia) y el segundo, el incumplimiento del convenio ${ }^{63}$. Hemos de tener en cuenta que el artículo 142.2 LC recoge como presupuestos del nuevo concurso (i) la imposibilidad de cumplir los pagos prometidos (en el convenio) y (ii) el incumplimiento de las obligaciones posteriores al convenio. En este segundo caso, en el que solamente se incumplen obligaciones posteriores, no podemos hablar técnicamente de incumplimiento del convenio, ya que el convenio no vincula a los acreedores que lo sean con posterioridad a su aprobación. Evidentemente, la incapacidad hacer frente a las obligaciones posteriores evidencia un déficit de tesorería que podrá acabar afectando al regular cumplimiento de las obligaciones derivadas del convenio, pero ello no implica que no sean situaciones conceptualmente diferentes.

Sin embargo, la LC se refiere exclusivamente en su regulación al incumplimiento del convenio, como se extrae del propio artículo 167.2 LC: $<<$ En caso de reapertura de la sección de calificación por incumplimiento de convenio, se procederá del siguiente modo >>.

En lo relativo a la tramitación de la sección reabierta o pieza separada, partimos de las disposiciones contenidas en los artículos 168.2 y 169.3 LC. Estos apartados vienen a restringir el ámbito material sobre el que versarán las alegaciones de los interesados, el informe de la administración concursal y el dictamen del Ministerio Fiscal. Se establece que tales escritos se limitarán a determinar (i) las causas del incumplimiento del convenio y (ii) si el concurso debe ser calificado como culpable en razón de incumplimiento por causa imputable al concursado ${ }^{64}$. Por último hemos de destacar que, puesto que la apertura y la reapertura tienen fundamentos diferentes (lo que justifica la posible coexistencia de dos pronunciamientos al respecto), también los supuestos que determinan la calificación del concurso como culpable deben ser aplicados con cautela. Es más, no todas las presunciones iuris et de iure contenidas en el artículo 164.2 LC podrán ser tenidas en consideración para generar una calificación automática del concurso.

Resulta imprescindible citar la Sentencia del Tribunal Supremo de 13 de abril de $2016^{65}$, que trata precisamente la cuestión de si cabe extender y

http://www.cuatrecasas.com/media_repository/docs/esp/la_calificacion_por_incumplimie nto_sobrevenido_del_convenio_concursal_especialmente_gravoso_971.pdf (consultado: 19.02.2018).

63 B. A. GONZÁLEZ NAVARRO, La Calificación por Incumplimiento Sobrevenido del Convenio Concursal Especialmente Gravoso, op. cit., pp. 4-5.

${ }^{64}$ Recordemos que el objeto de la sección sexta en los casos de mera apertura llega a abarcar cualquier circunstancia relativa a la calificación del concurso, relacionada con la generación o agravación del estado de insolvencia concurriendo dolo o culpa grave de las personas eventualmente responsables.

${ }^{65}$ Sentencia del Tribunal Supremo 246/2016, de 13 de abril de 2016, Sala de lo Civil (RC 2910/2013), ponente: PEDRO JOSE VELA TORRES. Id Cendoj: 28079119912016100007. 
en qué medida las presunciones legales de los artículos 164 y 165 LC a los supuestos de reapertura y liquidación ${ }^{66}$ :

$<<E l$ retraso en la solicitud de la liquidación carece de encaje en el artículo $165.1^{\circ}$ LC. La solicitud tardía de la liquidación no está prevista específicamente en la Ley como causa de culpabilidad del concurso, sin que quepa una traslación directa al tipo del mencionado art. $165.1^{\circ} \mathrm{LC}$, previsto para una situación distinta, el retraso en la solicitud de declaración de concurso, que no puede ser objeto de aplicación extensiva, atendida la naturaleza de la calificación concursal (analogía in malam partem); máxime si, como consecuencia necesaria de la calificación de culpabilidad, se deben imponer sanciones de inhabilitación para administrar bienes ajenos y para representar a terceros (art. 172.2.2० LC ) y privación de derechos económicos en el concurso (art. 172.2.3 LC). La norma del art. $165.1^{\circ}$ LC, que tipifica la falta de solicitud de la declaración de concurso, se aplica en conexión con lo dispuesto en el artículo 5.1 LC, que impone al deudor el deber de solicitar la declaración de concurso dentro de los dos meses siguientes a la fecha en que hubiera conocido o debido conocer su estado de insolvencia. Pero el art. 142.2 LC, a diferencia de dicho art. 5.1, no obliga al deudor a solicitar la liquidación a los dos meses de advertir la insolvencia - o la agravación de la insolvencia- sino "cuando, durante la vigencia del convenio, conozca la imposibilidad de cumplir los pagos comprometidos y las obligaciones contraídas con posterioridad a la aprobación de aquél">>.

Consecuentemente, procede el Alto Tribunal a fijar su doctrina del siguiente modo: $<<L a$ calificación tras la reapertura por incumplimiento o imposibilidad de cumplimiento del convenio debe ser enjuiciada únicamente desde la perspectiva de los arts. 164.2.3

${ }^{66}$ Esta Sentencia acoge además lo expuesto en relación con el concepto de fracaso del convenio, y de cómo la sustanciación de la reapertura, en tanto que ésta está dirigida tanto al incumplimiento estricto del convenio como a la imposibilidad de cumplimiento, debe incluir en ambos casos la restricción respecto de su objeto ex artículo 167.2 LC:

$<<$ De la literalidad del art. 167.2 LC pudiera parecer que la meritada limitación de enjuiciamiento únicamente se refiere a los casos de reapertura de la sección por incumplimiento del convenio, ya que no menciona la reapertura por imposibilidad de incumplimiento. Sin embargo, la identidad de razón entre ambos supuestos es manifiesta, puesto que los dos -incumplimiento e imposibilidad de cumplimiento- tienen un sustrato común, que es la frustración del cumplimiento del convenio, que conlleva el comienzo de la fase de liquidación y, con ella, la reapertura de la sección de calificación, y la necesidad de coordinar dicha reapertura con lo actuado en la tramitación inicial de la calificación.

En ambos casos está justificado que con la reapertura de la sección de calificación se enjuicien las causas que hubieran motivado que el convenio no se cumpliera, sin que tenga sentido ampliar las causas o motivos de enjuiciamiento en el supuesto en que el deudor, al apercibirse de la imposibilidad de cumplimiento, inste la apertura de la fase de liquidación, en vez de esperar al incumplimiento y suscitar un incidente concursal para la rescisión del convenio.

De no ser así, se haría de peor condición al deudor que se adelanta a abrir la liquidación cuando advierte que no puede cumplir el convenio, que al deudor que espera a que el incumplimiento sea una realidad y a que se ejercite por los legitimados para ello la consiguiente acción de declaración de incumplimiento y de resolución del convenio >>. 
o, 167.2, 168.2 y 169.3 LC. Lo que supone que, respecto de las causas de calificación, el ámbito de conocimiento en la sección reabierta se ciñe necesaria y exclusivamente a la determinación de si la frustración del cumplimiento del convenio es imputable al deudor concursado $>>$.

También puede interpretarse esta sentencia sensu contrario, para determinar que, en los casos de apertura de la sección sexta por incumplimiento de un convenio no gravoso, podrá efectivamente el tribunal valorar todas las cuestiones que no pudo en su día, entre las cuales habrá que incluir todas las presunciones legales, así como la cláusula general de los actos generadores o agravadores de la insolvencia.

\section{CONCLUSIONES}

Hemos ido comprobando a lo largo del presente trabajo que regulación del funcionamiento de la sección sexta dista bastante de ser exhaustiva o siquiera precisa. Nos vemos obligados cada vez que surge un vacío legal o una incongruencia a recurrir bien a la interpretación sistemática, ya que la teleológica no parece que tenga mucha cabida, o incluso, en algunos casos, la histórica. Al mismo problema se enfrentan tanto la doctrina académica como la judicial, llegando a suscitarse debates que, por enriquecedores que puedan ser, no alcanzan a sustituir la propia mano del legislador, quien, por cierto, ha tenido múltiples ocasiones para poner orden en el Capítulo II del Título VI de la LC.

Estos debates se han trasladado íntegramente, en algún caso señalado, a la esfera judicial, llegando a coexistir varios pronunciamientos contradictorios entre algunas Audiencias Provinciales y Juzgados. También el Tribunal Supremo ha tenido que entrar a interpretar de ley en ocasiones de una forma prácticamente creadora de derecho. Por ejemplo, en lo relativo a la calidad de parte procesal de los acreedores e interesados en el procedimiento, sobre si era posible determinar que éstos sostuvieran una determinada calificación en la sección sexta, y si por tanto, su escrito de hechos relevantes podía incluir un petitum de eficacia procesal.

Por otro lado, también hay que decir que algunos aspectos de las reformas, particularmente las del 2011 en adelante, sí aportan una visión que considero decisiva y necesaria para la modernización del derecho concursal. Los supuestos de liquidación se tratan, en general, mucho más severamente, mientras que si se alcanza el convenio las consecuencias concursales tienden a suavizarse. La eliminación de la apertura de la sección sexta en caso de convenios no gravosos es un ejemplo, como también lo es la posibilidad de que, en caso de convenio, la sentencia que declara la inhabilitación pueda autorizar al inhabilitado a permanecer al frente de la empresa, si así lo solicita la administración concursal.

No obstante, son muchas las cuestiones que siguen todavía sin una respuesta contundente por parte de los tribunales, en algunos casos porque ciertamente no se han llegado a plantear todavía y en otros porque no existe jurisprudencia consolidada, pero ello no resta gravedad a las objeciones que se plantean al articulado de la ley. Cuestiones todavía dudosas pueden ser la extensión subjetiva de los llamados "titulares de interés legítimo", el momento procesal de petición y admisión de la 
prueba, si cabe trámite de conclusiones, si la inhabilitación puede ser impuesta por el juez aunque no lo soliciten las partes, y un largo etcétera. No sorprenderá al lector mi valoración de la calidad técnica de la ley puesto que una gran parte de este estudio va encaminada a intentar desenredar de alguna manera la maraña que se oculta tras un articulado aparentemente sencillo. He procurado ir profundizando en los problemas interpretativos así como en las posibles soluciones, sugiriendo otros temas que pueden resultar de interés en la práctica, como por ejemplo la pérdida del interés litigioso de los interesados en la sección sexta.

En definitiva, no es impertinente exigir del legislador una mayor claridad y sistematización de las normas de la sección sexta en aras de una mayor seguridad jurídica, especialmente en un ámbito que se encuentra muy próximo al derecho sancionador, pues como dijo el filósofo y matemático británico Bertrand Russell, "lo que los hombres realmente quieren no es el conocimiento, sino la certidumbre".

\section{BIBLIOGRAFÍA}

J. AZAGRA, R. TAGLIAVINI, La posición procesal del adquirente de unidades productivas en concurso de acreedores, Uría Menéndez, disponible en:

http://www.uria.com/documentos/publicaciones/4290/documento/tavUM. pdf?id=5502 (Consultado 19.02.2018)

J. DE MIQUEL BERENGUER: La Pieza de Calificación en el Concurso de Acreedores, Bosch, Barcelona, 2012.

M. A. DÍAZ GÓMEZ, C. MIGUÉLEZ DEL RÍO, "La Calificación del Concurso Tras la Reforma Introducida en la Ley Concursal por la Ley 38/2011", Revista Pecvnia, núm. 14, 2012, pp. 145-168.

S. FRAU I GAIÀ, La Calificación en el Concurso de Acreedores. Una visión crítica, Tirant lo Blanch, Valencia, 2014.

B. GONZÁLEZ NAVARRO, "Los aspectos procesales más relevantes de la reforma de la Ley Concursal abril 2009", Revista Aranzadi Doctrinal, núm. 4/2009 (BIB 2009, 686).

M. I. HUERTA VIESCA, D. RODRÍGUEZ RUIZ DE VILLA, "El plazo para la emisión del informe-demanda de calificación concursal del artículo 169.1 LC", Diario La Ley, No 8527, Sección Tribuna, 27 de Abril de 2015, Ref. D-159, La Ley.

J. MACHADO PLAZAS, Derecho Concursal, Tirant lo Blanch, Valencia, 2012.

A. MUÑOZ PAREDES, P. PRENDES, Tratado Judicial de la Insolvencia, Thompson Reuters, Tomo II, 2012.

C. NIETO DELGADO, C, "La Calificación del Concurso", en VVAA; Tratado Práctico del Derecho Concursal y Su Reforma (Dir. MARTINEZ SANZ, F.), Tecnos, Madrid, 2012.

S. OLIVER BARCELÓ, "Comentario al art. 169 LC" en J. PULGAR EZQUERRA, C. ALONSO LEDESMA, A. ALONSO UREBA, G. ALCOCER GARAU, Comentarios a la Legislación Concursal, Registradores de España/Dykinson, Madrid, 2004. 
E. RODRIGUEZ ACHÚTEGUI, "Reformas Procesales del Real Decreto-ley 3/2009 en la Ley Concursal", Revista Aranzadi Doctrinal, núm. 5/2009 (BIB 2009, 686).

C. ROSENDE VILLAR, "Comentario al artículo 168. Personación y condición de parte", en VVAA; Comentarios a la Ley Concursal (Dir. CORDÓN MORENO, F.), Tomo II, Aranzadi, Navarra, 2010, $2^{\text {a }}$ Edición.

P. YANES YANES, "La Calificación Concursal", en VVAA; El Concurso de Acreedores (Dir. J. PULGAR IZQUERDO), La Ley, Madrid, 2012. 